FACULDADE DE FILOSOFIA, CIÊNCIAS E LETRAS DE RIBEIRÃO PRETO DEPARTAMENTO DE PSICOLOGIA PROGRAMA DE PÓS-GRADUAÇÃO EM PSICOBIOLOGIA

\title{
Comparação de procedimentos de ensino de relações nome-face para idosos saudáveis
}

\author{
Maria Cláudia Medeiros Ristum
}

Dissertação apresentada à Faculdade de Filosofia, Ciências e Letras de Ribeirão Preto da USP, como parte das exigências para obtenção do título de Mestre em Ciências, Área: Psicobiologia.

Ribeirão Preto - SP

2019 
FACULDADE DE FILOSOFIA, CIÊNCIAS E LETRAS DE RIBEIRÃO PRETO DEPARTAMENTO DE PSICOLOGIA PROGRAMA DE PÓS-GRADUAÇÃO EM PSICOBIOLOGIA

\title{
Comparação de procedimentos de ensino de relações nome-face para idosos saudáveis
}

\author{
Maria Cláudia Medeiros Ristum
}

Dissertação apresentada à Faculdade de Filosofia, Ciências e Letras de Ribeirão Preto da USP, como parte das exigências para obtenção do título de Mestre em Ciências, Área: Psicobiologia.

Orientadora: $\operatorname{Prof}^{\mathrm{a}} \operatorname{Dr}^{\mathrm{a}}$ Andréia Schmidt

Ribeirão Preto - SP 
Autorizo a reprodução e divulgação total ou parcial deste trabalho, por qualquer meio convencional ou eletrônico, para fins de estudo e pesquisa, desde que citada a fonte.

FICHA CATALOGRÁFICA

Ristum, Maria Cláudia Medeiros

Comparação de procedimentos de ensino de relações nome-face para idosos saudáveis. Ribeirão Preto, 2019.

62 p. : il. ; $30 \mathrm{~cm}$

Dissertação de Mestrado, apresentada à Faculdade de Filosofia, Ciências e Letras de Ribeirão Preto/USP. Área de concentração: Psicobiologia

Orientadora: Schmidt, Andréia.

1. Arbitrary Matching-to-Sample. 2. Pareamento Ostensivo. 3. Equivalência de Estímulos. 4. Relações Condicionais Arbitrárias. 5. Idosos. 


\section{DEDICATÓRIA}

Dedico o meu trabalho à minha mãe, Neusa Medeiros, que já começa a esquecer o meu nome, mas todos os dias ainda lembra da minha capacidade.

\section{ETERNAMENTE GRATA!}




\section{AGRADECIMENTOS}

À minha orientadora, Andréia Schmidt, por ter acreditado em mim todas as vezes que eu não acreditei, e tornar possível a realização desse sonho.

À Renata, pelo suporte emocional nos momentos mais difíceis, dividindo experiências de superação e coragem...

À Ana, mais que uma terapeuta ocupacional, um exemplo de mulher, mãe, profissional... Pessoa incrível que marcou minha vida para sempre!

Ao Rodrigo, que me mostrou uma psicologia humanizada, completamente diferente de tudo o que eu havia aprendido, e que vale a pena!

À Ju, minha amiga querida, sempre presente nos momentos de alegria e de dificuldade, trazendo confiança da forma mais carinhosa possível.

Ao meu pai, que ainda me abriga em sua casa para que eu consiga ir atrás dos meus sonhos.

Ao meu anjo da guarda, que me atura 24 horas por dia, todos os dias. Provavelmente um dos que mais tem trabalho! Quando tudo acaba, sempre me mostra que valeu a pena, mas que o sofrimento poderia ter sido menor... Prometo que um dia vou aprender!!! 


\section{SUMÁRIO}

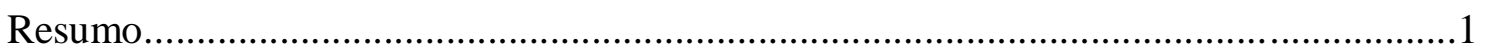

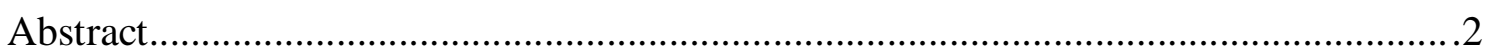

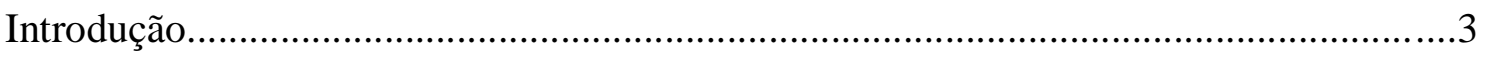

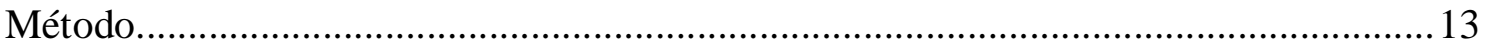

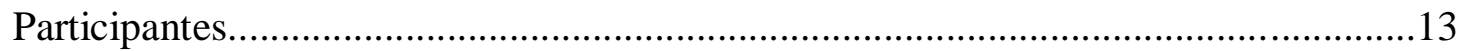

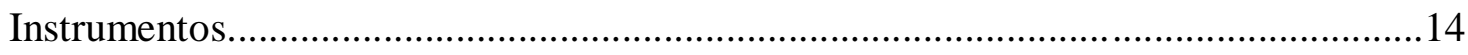

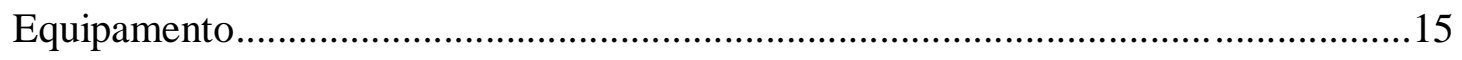

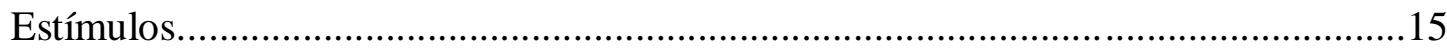

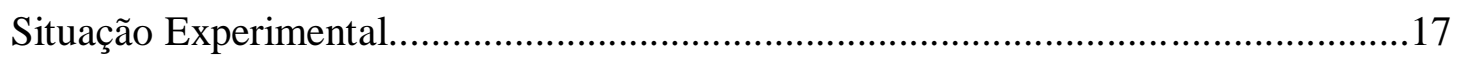

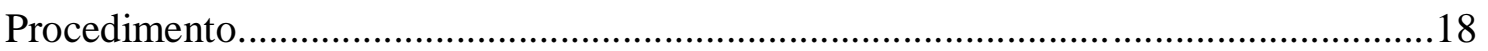

Fase 1 - Testes de Reconhecimento e Nomeação....................................................18

Fase 2 - Ensino e Testes das relações AB e AC, FG e FH, Testes de Nomeação, e Testes

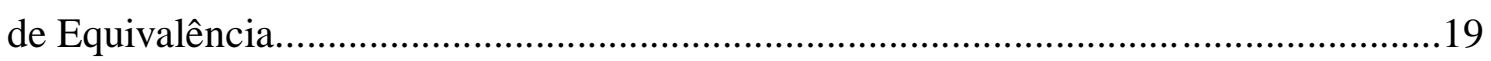

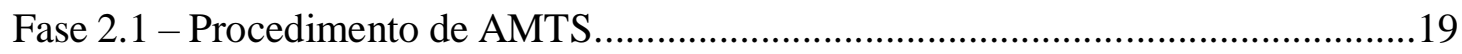

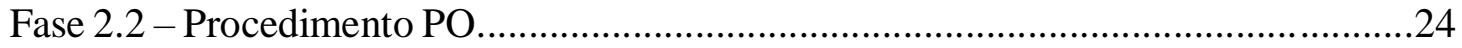

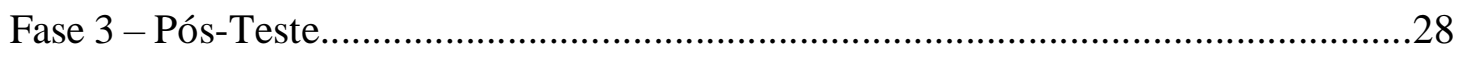

Fase 3.1 - Teste de Manutenção das relações AB, AC, BC e CB.................................28

Fase 3.2 - Teste de Manutenção das Relações FG, FH, GH e HG................................28

Fase 3.3 - Teste de Manutenção do Desempenho de Nomeação...................................28

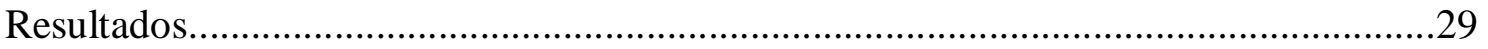

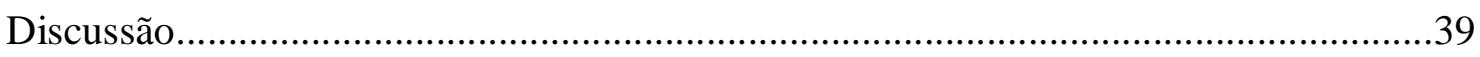

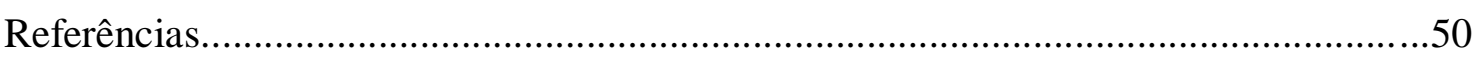

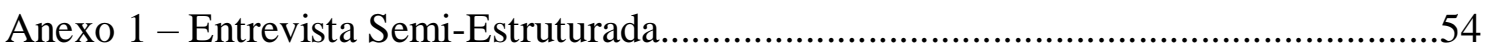

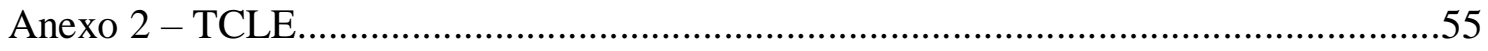


Ristum, M. C. M. (2019). Comparação de procedimentos de ensino de relações nomeface para idosos saudáveis. Dissertação de Mestrado, Programa de Pós-Graduação em Psicobiologia, Universidade de São Paulo, Ribeirão Preto-SP.

\section{Resumo}

O aumento na população idosa tem sido observado em todo o mundo, e uma das principais consequências dessa realidade é o aumento das demandas no âmbito da saúde. A demência está entre as doenças que mais afetam os idosos, demandando pesquisas sobre intervenções não farmacológicas que atuem na promoção e manutenção de habilidades linguísticas e cognitivas desses idosos. Pesquisadores da área da Análise do Comportamento têm proposto estudos sobre a formação de classes de estímulos equivalentes envolvidos em relações simbólicas, e que são formados a partir do estabelecimento de relações condicionais entre estímulos. Alguns procedimentos para o ensino de relações condicionais arbitrárias já foram desenvolvidos com diversas populações, mas ainda devem ser estudados com idosos. O presente estudo tem como objetivos: (a) comparar dois procedimentos de ensino, o arbitrary matching-to-sample (AMTS) associado ao ensino por exclusão, e o pareamento ostensivo (PO), em idosos saudáveis; (b) verificar a eficácia de cada procedimento na aprendizagem e manutenção de relações condicionais arbitrárias entre nomes e faces; (c) analisar a ocorrência de desempenhos emergentes em testes de equivalência de estímulos e de nomeação. Participaram deste estudo 12 idosos saudáveis, divididos em 2 grupos, que diferiam entre si apenas pela ordem de apresentação dos procedimentos de ensino: o grupo 1 começou com o procedimento de AMTS, e o grupo 2 com o procedimento de PO. Foram ensinadas quatro relações auditivo-visuais entre nomes ditados e fotos de mulheres desconhecidas (AB), e entre esses nomes ditados e seus correspondentes escritos (AC), seguido por testes de nomeação e de equivalência. Todos os participantes aprenderam todas as relações pelos dois procedimentos de ensino, não sendo verificadas diferenças entre os procedimentos de ensino, mas os idosos com menor escolaridade repetiram mais blocos de ensino, em comparação com os idosos mais escolarizados. Verificou-se emergência de formação de classes de equivalência em todos os idosos, assim como nomeação das fotos logo após o ensino. Nos testes de manutenção, porém, houve piora no desempenho dos idosos nos testes de nomeação. A piora foi maior para os idosos com menor escolaridade, e no procedimento de AMTS. Discute-se o papel da escolaridade no desempenho de idosos em procedimentos de ensino de relações condicionais.

Palavras-chave: arbitrary matching-to-sample, pareamento ostensivo, equivalência de estímulos, relações condicionais arbitrárias, idosos. 
Ristum, M. C. M. (2019). Comparação de procedimentos de ensino de relações nomeface para idosos saudáveis. Dissertação de Mestrado, Programa de Pós-Graduação em Psicobiologia, Universidade de São Paulo, Ribeirão Preto-SP.

\begin{abstract}
The increase in the elderly population has been observed all over the world, and one of the main consequences of this reality is the increasing demands on health. Dementia is among the diseases that most affect the elderly, demanding research on nonpharmacological interventions that promote and maintain the linguistic and cognitive abilities of these elderly people. Researchers in the area of Behavior Analysis have proposed studies on the formation of stimulus equivalence classes involved in symbolic relations, formed from the establishment of conditional relations between stimuli. Some procedures for teaching arbitrary conditional relations have been developed with several populations, but still have to be studied with the elderly. This study aims to: (a) compare two teaching procedures, the arbitrary matching-to-sample (AMTS) associated with responding by exclusion, and ostensive pairing (OP) in healthy elderly; (b) verify the effectiveness of each procedure in learning and maintaining arbitrary conditional relations between names and faces; (c) analyze the occurrence of emergent performances in stimulus equivalence and naming tests. The participants of this study were twelve healthy elderly people, divided into 2 groups that differed only in the order of presentation of the teaching procedures: group 1 started with the AMTS procedure, and group 2 with the PO procedure. Four auditory-visual relations between dictated names and photos of unknown women $(\mathrm{AB})$, and between those dictated names and their corresponding writing names (AC) were taught, followed by naming and equivalence tests. All the participants learned all the relations by the two teaching procedures, not being verified differences between them; but the elderly with less schooling repeated more learning blocks, in comparison with the more educated elderly. It was verified the emergence of equivalence class formation in all the participants, as well as the naming of the photos right after each teaching procedure. In the maintenance tests, however, there was decrease in the performance of the elderly in the naming tests. The decrease was greater for the elderly with less schooling, and in the AMTS procedure. The role of schooling in the performance of the elderly in procedures of teaching conditional relations is discussed.
\end{abstract}

Keywords: arbitrary matching-to-sample, ostensive pairing, stimulus equivalence, arbitrary conditional relations, elderly. 


\section{Introdução}

O aumento na população idosa tem sido observado em todo o mundo, e estima-se que entre 2015 e 2050, a porcentagem de idosos irá aumentar de $12 \%$ para $22 \%$ (World Health Organization [WHO], 2016). No Brasil, o segmento da população que mais aumenta é o de idosos, com taxas de crescimento de mais de $4 \%$ ao ano no período de 2012 a 2022; estimativas indicam que essa população passará de 19,6 milhões em 2010, para 73,5 milhões em 2060 (Instituto Brasileiro de Geografia e Estatística [IBGE], 2015).

Dados mais recentes mostram que apenas no intervalo entre os anos de 2012 a 2017, o Brasil ganhou 4,8 milhões de idosos, superando a marca de 30,2 milhões em 2017 (IBGE, 2018).

Uma das principais consequências dessa realidade é o aumento das demandas no âmbito da saúde, com necessidade de especialidades médicas e terapêuticas preparadas para lidar com prejuízos físicos, cognitivos e sócio emocionais dos idosos. Estudos sobre a caracterização da população idosa no mundo todo avaliam que há cerca de 50 milhões de pessoas com algum tipo de demência, sendo que $60 \%$ desse total vive em países com baixa ou média renda. Todos os anos há aproximadamente 10 milhões de novos casos, e estima-se que a proporção da população com 60 anos de idade ou mais, com demência, está entre cinco a oito indivíduos para cada 100 (WHO, 2017).

Por se tratar de uma doença reconhecida e estudada há relativamente pouco tempo, há urgência na realização de pesquisas que promovam maior conhecimento no âmbito clínico para seu correto diagnóstico e tratamento.

Mesmo em idosos que apresentam um envelhecimento saudável, ocorre um processo gradativo e inevitável de danos nas estruturas do Sistema Nervoso Central (SNC). Há uma redução considerável do volume do encéfalo com a idade, assim como a 
diminuição da arborização dos neurônios e da densidade das conexões sinápticas (Yeoman, Scutt, \& Faragher, 2012). Porém, essas perdas não atingem todo o SNC de forma homogênea, além de haver diferenças individuais nesse processo. Geralmente, observa-se um maior declínio em áreas responsáveis pelas funções cognitivas de execução de tarefas, velocidade de processamento, e memória episódica (Rabitt \& Lowe, 2006). Por se tratarem das queixas mais recorrentes entre os pacientes idosos, sobretudo em relação à memória, há uma dificuldade maior do profissional da área da saúde em avaliar a linha tênue entre o envelhecimento normal e o início de algum transtorno neurocognitivo (Porto \& Nitrini, 2014).

Diante dessa realidade, a necessidade de intervenções terapêuticas em estágios iniciais do declínio cognitivo é primordial na manutenção da autonomia desses idosos por um período de tempo maior. Além do tratamento farmacológico, uma das intervenções mais utilizadas é a Reabilitação Neuropsicológica, cujos objetivos consistem na reinserção social do idoso e promoção de maior independência na realização de suas atividades, através de técnicas que reabilitem sua cognição e comunicação (Brandão et al. 2014).

Simon e Ribeiro (2011) realizaram uma revisão bibliográfica com o objetivo de investigar os benefícios da reabilitação neuropsicológica em idosos diagnosticados com TNCL. Foram revisados 15 estudos, publicados entre 2002 e maio de 2009, que comprovaram a melhora das funções cognitivas, tais como memória episódica e operacional, praxia construtiva, aprendizado psicomotor, raciocínio e velocidade de processamento. Porém, os autores ressaltaram as diversas limitações metodológicas na comparação entre esses estudos, como os diferentes tipos de intervenção utilizados. A maioria dos estudos (12) empregou o Treino Cognitivo, mas houve diferenças entre as técnicas utilizadas e os domínios cognitivos avaliados; outros dois estudos empregaram 
a Reabilitação Cognitiva, entretanto, cada estudo fez uso de técnicas de aprendizagem diferentes; e apenas um estudo utilizou a Psicoterapia Cognitivo-Comportamental como intervenção, com o objetivo de ensinar o idoso como lidar com os sintomas do TNC e com suas consequências. Diante da dificuldade em comparar os resultados desses estudos, os autores recomendaram a realização de pesquisas com maior controle metodológico, principalmente com relação aos instrumentos de intervenção utilizados e aos domínios cognitivos trabalhados.

Mais recentemente, pesquisadores da área da Análise do Comportamento têm proposto estudos sobre as funções cognitivas e suas alterações por meio do paradigma da Equivalência de Estímulos (de Rose, 1993; Sidman \& Tailby, 1982). Esse paradigma permite avaliar a formação e manutenção de relações simbólicas entre estímulos: quando dois ou mais estímulos estão relacionados (e.g., uma palavra ditada, essa mesma palavra escrita, e sua figura correspondente), eles constituem classes de estímulos equivalentes cuja relação pode ser considerada simbólica.

Compreender relações simbólicas entre estímulos é importante para o dia a dia de um indivíduo pois lhe permite operar com estímulos ausentes - símbolos - que podem ser substituídos por estímulos equivalentes (de Rose \& Bortoloti, 2007). Um indivíduo, por exemplo, pode falar sobre uma máquina fotográfica que não está presente naquele ambiente, para instruir outro indivíduo sobre como operá-la; a palavra ditada, nesse caso, substitui o objeto concreto nesse contexto específico.

O estabelecimento de relações de equivalência envolvendo estímulos verbais e diferentes aspectos do mundo também pode estar relacionado diretamente com um dos aspectos essenciais da linguagem: o significado (Sidman, 1994). De acordo com de Rose (1993), “dizer que uma palavra tem um significado implica em que esta palavra é um 
estímulo equivalente a um conjunto de estímulos (...). Estas relações de equivalência permitem a produção e a compreensão da linguagem" (p. 294).

Para que estímulos relacionados condicionalmente formem uma classe de equivalência, são necessárias três propriedades entre eles: simetria, transitividade e reflexividade (Sidman, \& Tailby, 1982). Se considerarmos dois estímulos pertencentes a dois conjuntos (Conjunto A e Conjunto B), a relação entre eles será simétrica quando um elemento do conjunto A mantiver uma relação " $r$ " com um elemento do conjunto $\mathrm{B}$, e este elemento de B mantiver a mesma relação " $r$ " com aquele elemento do conjunto A. A reflexividade ocorre quando a relação de um elemento do conjunto A com ele próprio é verdadeira (por exemplo, "x" é igual a "x"). E a transitividade ocorre quando consideramos três conjuntos (A, B e C) e, após a validação das relações entre elementos de A com elementos de B, e entre elementos do conjunto A com os do conjunto $\mathrm{C}$, verificamos a validade da relação entre os conjuntos B e C (de Rose, 1993).

Com base nessas três propriedades, o ensino direto das relações entre os elementos dos Conjuntos A e B, e entre elementos de A e C, resulta na aprendizagem de relações que não foram ensinadas anteriormente, denominadas desempenhos emergentes (Sidman \& Tailby, 1982). Os estudos sobre equivalência de estímulos utilizam uma metodologia que inclui o ensino de relações condicionais entre estímulos de diferentes conjuntos, e a realização de testes para verificar a presença de desempenhos emergentes (de Rose, 1993).

Um dos procedimentos mais comuns para estabelecer relações condicionais diretas entre estímulos arbitrários é o pareamento arbitrário com o modelo (arbitrary matching to sample - AMTS). Esse procedimento é realizado com um conjunto de estímulos modelo e um conjunto de estímulos de comparação, de forma que cada elemento do conjunto dos modelos seja condicionalmente relacionado a um estímulo do 
conjunto de comparações. A tarefa envolve a escolha de um entre dois ou mais estímulos de comparação que seja condicional ao estímulo modelo apresentado (de Rose, 1993). Assim, se o modelo apresentado fizer parte do Conjunto A (e.g., A1), e os estímulos de comparação forem do Conjunto B, a escolha correta será o elemento 1 de B (B1).

Embora seja um procedimento muito utilizado pelos analistas do comportamento, um número reduzido de pesquisas tem testado procedimentos de AMTS para estabelecer relações arbitrárias entre estímulos com participantes idosos, com ou sem déficits cognitivos (e.g., Aggio \& Domeninconi, 2012; Ducatti \& Schmidt, 2016; Haydu \& Morais, 2009). Além disso, os resultados desses estudos são variáveis, pois apresentam diferenças nos tipos de estímulos utilizados, na quantidade de estímulos e de classes, na estrutura do treino e dos testes, entre outros.

Um exemplo desse tipo de estudo é o de Aggio e Domeniconi (2012), no qual foram ensinadas relações condicionais entre figuras abstratas via AMTS para oito idosos saudáveis, divididos em dois grupos experimentais. No primeiro grupo foram ensinadas relações entre três classes com três estímulos cada (Condição 1), e no segundo, três classes com seis estímulos (Condição 2). Ao longo dos blocos de treino os estímulos de comparação foram inseridos gradualmente, iniciando sempre com uma tentativa de "escolha forçada" (com disponibilidade para resposta apenas sobre o estímulo correto), seguido de uma inserção gradual de comparações até chegar em três. Para cada relação havia dois blocos de treino com fading out de feedback. A média do número de tentativas de treino da relação BA e CA para os participantes da Condição 1 foi de 229 e 255 , respectivamente. Na Condição 2 as médias para BA, CA, DA, EA e FA foram 208, 214, 86, 46 e 30, respectivamente. Esses resultados mostraram uma diminuição no número de tentativas requeridas para que o critério fosse atingido, à medida em que novas relações foram sendo inseridas. Todos os participantes formaram as classes de equivalência, 
porém dois participantes de cada situação experimental precisaram repetir esse bloco algumas vezes. Após seis semanas foi realizado um teste de manutenção das relações; os participantes da Condição 1 apresentaram porcentagens de acertos entre 52\% e 63\%, enquanto na Condição 2 apenas um participante teve uma porcentagem de acerto inferior a 90\%. Segundo os pesquisadores, esse resultado demonstrou indícios de que a aprendizagem das relações nas classes com maior número de estímulos permaneceu mais estável ao longo do tempo.

Outro estudo que também avaliou a formação de relações arbitrárias entre estímulos através do AMTS foi realizado por Haydu e Morais (2009). Participaram 18 senhoras saudáveis, com idade média de 61 anos, que foram divididas em dois grupos com a mesma quantidade de blocos de ensino e de teste. O Grupo 1 passou pelo ensino de seis classes com seis estímulos cada, seguido pelo ensino de outras seis classes com quatro estímulos cada. Essa ordem de ensino foi trocada para o Grupo 2. Os estímulos consistiam em figuras de faces masculinas, e palavras escritas (nome masculino, uma profissão, uma ação, um objeto e um animal). Os resultados mostraram não haver relação entre a ordem de ensino das classes e os desempenhos das participantes; entretanto, a análise dos dados de recuperação das classes após seis semanas (Teste de Manutenção) mostrou que as participantes mantiveram a aprendizagem das relações para as classes formadas por 6 estímulos, mas não para as classes de 4 estímulos. Verificou-se que o tamanho das classes não afetou a formação das classes de equivalência, mas influenciou a manutenção das classes com mais estímulos.

Quando se trata de estudos com idosos com TNC, há um número ainda menor de estudos testando procedimentos de AMTS e, em geral, com um número reduzido de participantes. Os dois estudos de Steingrimsdottir e Arntzen (2011, 2014), por exemplo, foram conduzidos com apenas um participante; no primeiro estudo o participante não 
atingiu o critério de acertos na tarefa de AMTS, e no segundo estudo o participante atingiu o critério após vários ajustes dos procedimentos. No estudo de Ducatti e Schmidt (2016) participaram quatro idosas com $\mathrm{TNC}$, mas foram necessários vários ajustes de procedimento para que aprendessem as relações condicionais arbitrárias - o uso apenas do AMTS não foi eficiente para o ensino de relações condicionais entre nomes e faces para as idosas participantes.

Uma forma de auxiliar idosos com TNC na aprendizagem de relações condicionais é o uso de um procedimento de exclusão associado ao AMTS (Ducatti \& Schmidt, 2016). O procedimento de ensino por exclusão consiste na apresentação de um estímulo novo (desconhecido) junto com um ou mais estímulos conhecidos; diante da instrução "aponte o x" (estímulo modelo desconhecido), a escolha do indivíduo deverá ser pelo estímulo desconhecido, rejeitando ou excluindo os estímulos que ele já conhece (Dixon, 1977).

Apenas um estudo foi encontrado sobre responder por exclusão e formação de classes de equivalência com participantes idosos saudáveis, com comprometimento cognitivo leve (CCL), ou Doença de Alzheimer (DA), moradores de ILPIs (Ducatti \& Schmidt, 2016). Os resultados mostraram que os idosos saudáveis aprenderam relações condicionais arbitrárias por exclusão, não demonstraram dificuldade durante a aprendizagem, e conseguiram realizar os testes de equivalência. Os idosos com CCL ou DA aprenderam as relações por exclusão apenas nas tentativas em que o estímulo modelo novo era apresentado pela primeira vez; das seis participantes desse estudo, apenas duas mantiveram a aprendizagem das relações ao longo das demais tentativas. As pesquisadoras realizaram outro estudo com outras quatro participantes, com estrutura de treino um-para-muitos, procedimento de dica atrasada e ensino por exclusão; todas 
conseguiram aprender as relações, porém não apresentaram formação e manutenção de classes de equivalência.

Essa pesquisa foi importante para demostrar que o uso de procedimentos de ensino associados (e.g., AMTS, exclusão e dica atrasada) pode ser eficiente para a aprendizagem das relações condicionais arbitrárias por idosos com TCN, mas são necessários mais estudos para investigar outros procedimentos de ensino alternativos ao AMTS (ou complementares a ele) e investigar os motivos pelos quais a aprendizagem das relações condicionais não foi suficiente para sustentar a formação e manutenção de classes de equivalência em idosos com CCL e DA.

Um procedimento descrito na literatura para o ensino de relações arbitrárias entre estímulos é o Pareamento Ostensivo (PO). Stemmer (1992) introduziu o termo evento ostensivo (ostensive event) para se referir aos eventos nos quais ocorre o pareamento entre um estímulo verbal com um estímulo não verbal, dando origem ao comportamento de ouvinte. $\mathrm{O}$ autor se referia a este processo como uma ocorrência natural no cotidiano das crianças e que favoreceria o desenvolvimento de repertórios de ouvinte. Para Stemmer, a aprendizagem do comportamento verbal se dá por meio da exposição ao pareamento entre dois estímulos: o verbal e o não verbal. Num primeiro momento, o indivíduo passa a ser um ouvinte competente, pois é capaz de identificar o estímulo correto e emitir a palavra correta diante do estímulo. Essas seriam as condições necessárias para que esse ouvinte se tornasse um falante dessa palavra.

Os trabalhos de Stemmer e de outros autores que discutem essa teoria (e.g., Dahás, Goulart \& Souza, 2008; Souza, Miccione \& Assis, 2009; Vichi, Nascimento \& Souza, 2012) dão ênfase ao papel do ouvinte no comportamento verbal, e discutem que esse papel foi negligenciado por Skinner, em seu livro Verbal Behavior de 1957. Porém, estes autores não realizaram pesquisas empíricas para testar a eficácia do PO no ensino de 
novas relações condicionais. Duas pesquisas foram encontradas na literatura utilizando o PO como procedimento de ensino. No estudo de Sousa, Souza, \& Gil (2013) a participante tinha apenas 17 meses de idade, e os pesquisadores associaram o procedimento de PO com o MTS para o ensino das relações condicionais auditivo-visuais, verificando que o uso de PO antes do procedimento de MTS favoreceu a aprendizagem da criança. Em outro estudo, Fontanesi e Schmidt (2019) conduziram um procedimento de PO associado ao procedimento de AMTS por exclusão para favorecer a aprendizagem de oito relações condicionais entre palavras ditadas e figuras por uma idosa com afasia. O procedimento foi eficiente para o ensino de relações que a idosa, apenas pelo procedimento de AMTS, não havia aprendido.

O uso de procedimentos alternativos ao AMTS (ou associados a ele) necessitam, portanto, de um número maior de pesquisas para que possam beneficiar idosos que apresentam algum tipo de TNC. Para isso, porém, um primeiro passo deve ser a pesquisa desses procedimentos junto a idosos saudáveis. É importante analisar a eficácia de diferentes métodos de ensino para essa população, para que estudos futuros possam testar esses métodos comparando os desempenhos de idosos saudáveis e idosos com algum tipo de TNC. A longo prazo, espera-se que métodos de ensino/recuperação mais eficazes possam ser utilizados não apenas em procedimentos de reabilitação, mas também como instrumentos para avaliar indícios de demência em idosos.

Nessa direção, o presente estudo tem como objetivos: (a) comparar dois procedimentos de ensino, o AMTS associado ao ensino por exclusão, e o PO apresentado antes da tarefa de AMTS, em idosos saudáveis (que não apresentam indícios de TNC); (b) verificar a eficácia de cada procedimento na aprendizagem e manutenção de relações condicionais arbitrárias; (c) analisar a ocorrência de desempenhos emergentes em testes de equivalência de estímulos. 
No presente estudo, portanto, todos os idosos aprenderam dois conjuntos de relações entre nome e face. No ensino por AMTS os idosos aprenderam as relações em tarefas de AMTS associado ao ensino por exclusão, ou seja, inicialmente, as faces desconhecidas eram apresentadas como comparações junto a faces de pessoas conhecidas (mulheres famosas); gradualmente, essas faces conhecidas deixaram de ser apresentadas e o ensino/teste prosseguiu apenas com as faces de ensino. No procedimento de ensino por PO, os participantes foram expostos ao pareamento da relação nome/face pelo computador (a foto da face a ser aprendida era apresentada no centro da tela, enquanto um áudio com a repetição do nome da pessoa era apresentado em frases contendo informações a respeito da foto/pessoa). Após essa exposição, o participante passava por uma exposição à tarefa de AMTS (sem a associação do procedimento de exclusão) para aferir sua aprendizagem das relações ensinadas - nesse sentido, pode-se dizer que o PO foi um procedimento que antecedeu a tarefa de AMTS, ainda que esta última não tenha sido utilizada aqui como procedimento de ensino, mas apenas de teste. 


\section{MÉTODO}

\section{Participantes}

Participaram deste estudo 12 idosos saudáveis (11 mulheres), com idade entre 60 e 80 anos (média de 69,25 anos). Os critérios de exclusão da amostra foram: (a) escolaridade inferior a dois anos ou incapacidade de leitura; (b) uso de medicação que pudesse afetar a orientação e vigília; (c) dificuldades visuais, auditivas ou motoras que impossibilitassem a realização do procedimento; (d) indicativos de depressão; (e) pontuação no Mini Exame do Estado Mental (MEEM) menor que 18 para idosos com escolaridade entre 4 e 8 anos, e menor que 26 pontos para aqueles com escolaridade superior a 8 anos.

Os participantes foram aleatoriamente divididos em dois grupos, cuja diferença consiste na ordem de apresentação dos procedimentos de ensino para a aprendizagem das relações nome-face: Grupo Experimental 1 (GE1), composto por seis idosos, que passaram inicialmente pelo ensino por emparelhamento arbitrário com o modelo (AMTS) associado ao ensino por exclusão, e Grupo Experimental 2 (GE2), composto pelos outros seis idosos, designados para iniciar com o procedimento de ensino por pareamento ostensivo (PO).

A Tabela 1 mostra algumas informações relevantes sobre os participantes que aceitaram fazer parte deste estudo, e que não apresentaram os critérios de exclusão da amostra. Observe-se a maior representatividade das mulheres na amostra e o alto grau de escolaridade dos participantes, sendo que apenas quatro idosas cursaram parte do ensino fundamental, cinco concluíram o ensino médio, e três idosos completaram o ensino superior. A pontuação de todos os idosos no Mini Exame de Estado Mental foi maior que 26, sugerindo ausência de comprometimento cognitivo. 
Tabela 1.

Caracterização dos Participantes do Estudo

\begin{tabular}{|c|c|c|c|c|c|c|c|c|c|}
\hline $\mathrm{P}$ & Idade & $\mathrm{S}$ & $\begin{array}{l}\text { Estado } \\
\text { Civil }\end{array}$ & Escolarid. & MEEM & GDS & Grupo & Profissão & $\begin{array}{c}\text { Ocupação } \\
\text { Atual }\end{array}$ \\
\hline $\mathrm{P} 1$ & 62 & $\mathrm{~F}$ & Solteira & $\begin{array}{c}15 \text { anos } \\
\text { (ES) }\end{array}$ & 30 & 1 & 1 & psicóloga & psicóloga \\
\hline $\mathrm{P} 2$ & 65 & $\mathrm{~F}$ & Viúva & $\begin{array}{l}\text { (EM) } \\
11 \text { anos }\end{array}$ & 27 & 4 & 1 & dona de casa & aposentada \\
\hline $\mathrm{P} 3$ & 73 & $\mathrm{~F}$ & Casada & $\begin{array}{c}(\mathrm{EM}) \\
15 \text { anos }\end{array}$ & 29 & 4 & 2 & professora & aposentada \\
\hline P4 & 77 & M & Casado & $\begin{array}{c}(\mathrm{ES}) \\
15 \text { anos }\end{array}$ & 30 & 3 & 1 & engenheiro & engenheiro \\
\hline P5 & 61 & $\mathrm{~F}$ & Casada & $\begin{array}{c}(\mathrm{ES}) \\
11 \text { anos }\end{array}$ & 29 & 2 & 2 & enfermeira & $\begin{array}{c}\text { Enfermeira } \\
\text { dona de }\end{array}$ \\
\hline P6 & 75 & $\mathrm{~F}$ & Viúva & $\begin{array}{c}(\mathrm{EM}) \\
11 \text { anos }\end{array}$ & 26 & 1 & 2 & dona de casa & $\begin{array}{c}\text { casa } \\
\text { Aposentad }\end{array}$ \\
\hline P7 & 61 & $\mathrm{~F}$ & Casada & $(\mathrm{EM})$ & 29 & 2 & 1 & Aux. adm. & $\stackrel{\mathrm{a}}{\text { dona de }}$ \\
\hline P8 & 66 & $\mathrm{~F}$ & Casada & 7 anos & 29 & 2 & 2 & dona de casa & casa \\
\hline P9 & 73 & $\mathrm{~F}$ & Casada & 3 anos & 26 & 1 & 1 & vendedora & $\begin{array}{c}\text { Vendedora } \\
\text { dona de }\end{array}$ \\
\hline P10 & 80 & $\mathrm{~F}$ & & 4 anos & 29 & 1 & 2 & dona de casa & $\begin{array}{c}\text { casa } \\
\text { Aposentad }\end{array}$ \\
\hline P11 & 78 & $\mathrm{~F}$ & Viúva & $\begin{array}{l}4 \text { anos } \\
11 \text { anos }\end{array}$ & 27 & 3 & 1 & vendedora & $\stackrel{\text { a }}{\text { dona de }}$ \\
\hline $\mathrm{P} 12$ & 60 & $\mathrm{~F}$ & Casada & (EM) & $\frac{30}{10 r C o m n}$ & 2 & 2 & dona de casa & $\frac{\text { casa }}{2}$ \\
\hline
\end{tabular}

\section{Instrumentos}

Para a avaliação dos critérios de exclusão foram utilizados os seguintes instrumentos:

- Entrevista semi-estruturada (Anexo 1): continha questões sobre informações pessoais, sociais e de saúde do participante.

- Mini-Exame do Estado Mental (MEEM): constitui-se em uma escala de rastreamento cognitivo composta por questões agrupadas em sete categorias: orientação temporal (5 pontos), orientação espacial (5 pontos), registro de três palavras (3 pontos), atenção e cálculo (5 pontos), evocação das três palavras ( 3 pontos), linguagem ( 8 pontos) e capacidade visuo-construtiva ( 1 ponto). A pontuação pode variar de 0 a 30 . $O$ instrumento 
tem boa correlação com a evolução do processo demencial, desde que levado em consideração o grau de instrução do indivíduo para o ajuste dos pontos de corte. Analfabetos têm o escore de corte para indicação de comprometimento cognitivo de 13 pontos; indivíduos com escolaridade baixa (1 a 4 anos) e média (4 a 8 anos incompletos) têm o escore de corte de 18 pontos; e indivíduos com alta escolaridade (acima de 8 anos) possuem o escore de corte de 26 pontos (Folstein, Folstein, \& McHugh, 1975).

- Escala de Depressão Geriátrica - Versão reduzida (GDS-15): esta versão permite avaliar se o participante possui indício de depressão ou não; contém 15 itens em forma de perguntas, cujas respostas consistem em "sim" ou "não". A pontuação de corte que indica depressão é igual ou superior a 6; pontuação igual ou inferior a 5 indica ausência de depressão (Yesavage, Brink, Rose, Lum, Huang, Adey \& Leirer, 1983).

\section{Equipamento}

O equipamento utilizado para a apresentação dos estímulos foi um notebook Lenovo com tela sensível ao toque. Os estímulos empregados e as tarefas foram apresentados pelo software JClic (disponível em http://clic.xtec.cat/es/index.htm).

\section{Estímulos}

No total, foram utilizados 28 estímulos para os procedimentos de ensino empregados nos dois grupos de participantes (ver Tabela 2). Para o ensino por AMTS associado ao ensino por exclusão, foram empregados 16 estímulos, divididos em cinco conjuntos:

- Conjunto A: nomes ditados de mulheres desconhecidas (quatro estímulos auditivos);

- Conjunto B: fotos de mulheres desconhecidas (quatro estímulos visuais);

- Conjunto C: nomes escritos de mulheres desconhecidas (quatro estímulos visuais);

- Conjunto D: fotos de mulheres famosas (dois estímulos visuais);

- Conjunto E: nomes escritos de mulheres famosas (dois estímulos visuais). 
Outros 12 estímulos foram usados no procedimento de ensino por PO:

- Conjunto F: nomes ditados de mulheres desconhecidas (quatro estímulos auditivos);

- Conjunto G: fotos de mulheres desconhecidas (quatro estímulos visuais);

- Conjunto H: nomes escritos de mulheres desconhecidas (quatro estímulos visuais).

Tabela 2.

Estímulos Empregados nas Condições de Ensino por AMTS (Conjuntos A, B, C, D e E), e PO (Conjuntos F, G e H).

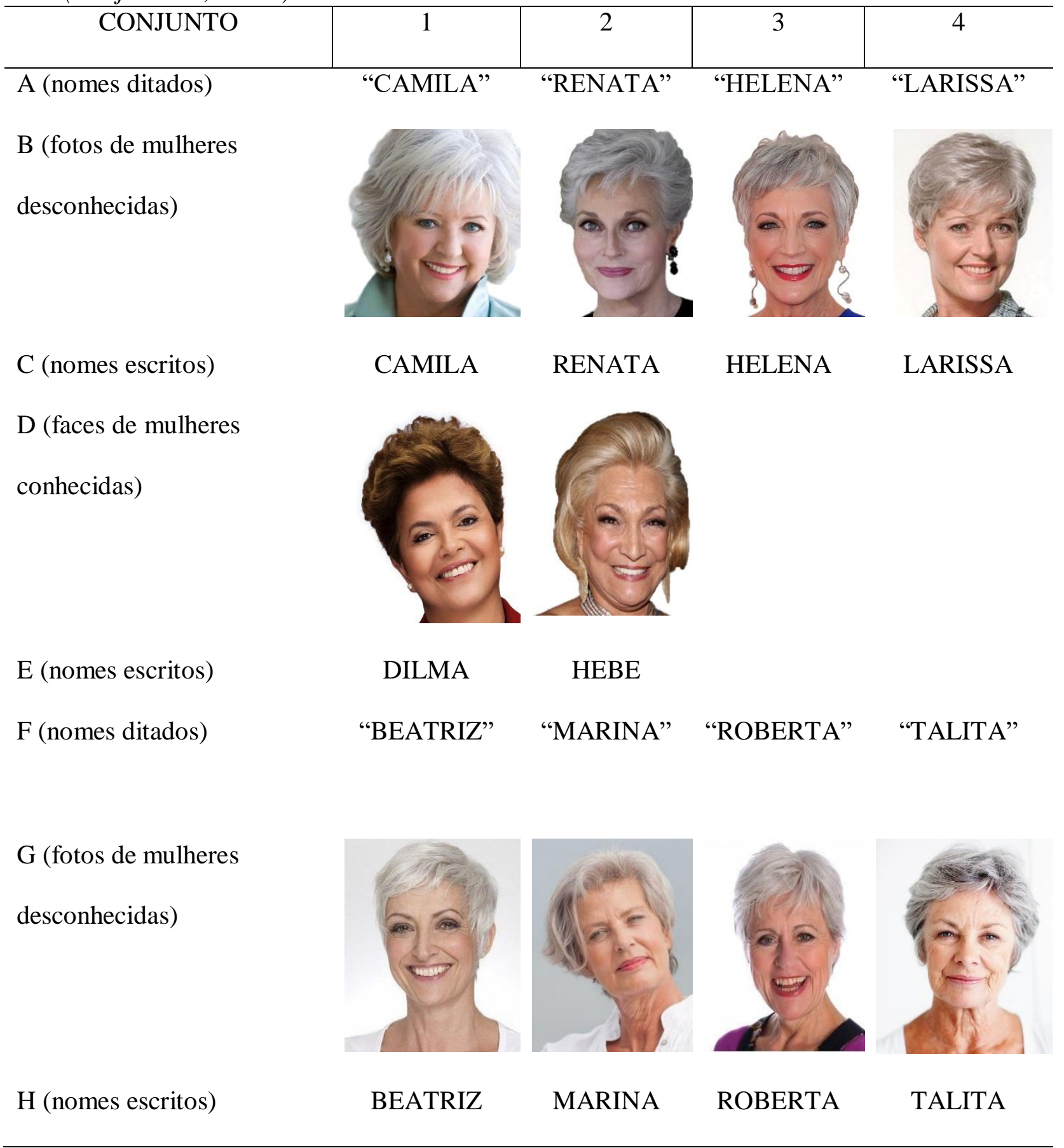


As fotos foram selecionadas a partir de bancos abertos na internet. Teve-se o cuidado para que as fotos fossem parecidas e que não apresentassem características muito distintivas que se constituíssem em eventuais dicas adicionais nas tarefas de aprendizagem. Os critérios de seleção para as fotos foram: ser uma foto da face de uma mulher idosa; todas terem cabelos brancos e curtos; o fundo da foto ser neutro e claro; as mulheres das fotos serem caucasianas. Os nomes das mulheres selecionadas para o estudo foram atribuídos de forma aleatória (por sorteio) entre as fotos, e todos eram constituídos por três sílabas.

Já em relação às fotos de mulheres conhecidas, a seleção foi realizada da seguinte forma: uma amostra de dez faces de mulheres com idade igual ou superior a 60 anos, consideradas famosas por um site de busca, foi apresentada no notebook para 10 idosos saudáveis e conhecidos pela pesquisadora, que não participaram da pesquisa. Eles tinham que nomear todas as faces que reconheciam, e dentre as dez, todos os idosos nomearam corretamente as faces da Dilma Roussef e Hebe Camargo. Como as outras faces não tiveram $100 \%$ de reconhecimento, foram selecionadas para o estudo as fotos de Dilma e Hebe.

\section{Situação Experimental}

A pesquisa foi realizada na casa dos participantes, em um espaço onde havia boa iluminação e pouco ou nenhum estímulo sonoro, uma mesa para apoiar o notebook e duas cadeiras. Quando outros moradores estavam na casa, a pesquisadora pedia para que não interrompessem o experimento. Também foi avisado aos participantes que poderiam parar ou dar uma pausa durante a sessão, garantindo seu bem-estar e disponibilidade. 


\section{Procedimento}

A pesquisa foi aprovada pelo Comitê de Ética em Pesquisa com Seres Humanos da Faculdade de Filosofia, Ciências e Letras de Ribeirão Preto - USP (CAAE 58786516.9.0000.5407).

Os idosos foram convidados a participar da pesquisa após uma breve explicação sobre o procedimento. Foi lido pela pesquisadora o Termo de Consentimento Livre e Esclarecido (TCLE - Anexo 2), contendo informações sobre a pesquisa. Após a concordância e assinatura desse Termo, cada participante respondeu à entrevista semiestruturada, seguida do MEEM e da GDS-15.

\section{Fase 1 - Testes de Reconhecimento e de Nomeação}

O objetivo dessa fase foi verificar se os participantes não conheciam as fotos das mulheres desconhecidas (conjuntos B e G), e se reconheciam as fotos de mulheres famosas (conjunto E). Para isso, os participantes passaram primeiro por um teste de reconhecimento, no qual foram apresentados na tela do computador os quatro estímulos do conjunto B, um em cada canto da tela do notebook; foi pedido para o participante selecionar aquele correspondente ao nome ditado (e.g., "aponte a Camila"). Foram realizadas oito tentativas, sendo duas para cada estímulo. A localização dos estímulos na tela foi diferente em cada tentativa e os modelos foram ditados de forma não consecutiva. Esse procedimento foi repetido com os estímulos do conjunto G.

Em seguida foi realizado um teste de nomeação, em que cada estímulo dos conjuntos B e G foram apresentados uma única vez, individualmente e no centro da tela, e foi pedido ao participante que o nomeasse (e.g., “qual é o nome dela?’).

Tanto o teste de reconhecimento, quanto o teste de nomeação foram realizados também com os estímulos familiares, para garantir que os participantes os reconheciam. 
Fase 2 - Ensino e Testes das relações AB e AC, FG e FH, Testes de Nomeação, e Testes de Equivalência

O objetivo dessa fase foi ensinar e testar oito relações arbitrárias entre nomes ditados e fotos (quatro relações $\mathrm{AB}$ e quatro relações $\mathrm{FG}$ ), e oito relações arbitrárias entre nomes ditados e nomes escritos (quatro entre $\mathrm{AC}$ e quatro entre $\mathrm{FH}$ ). As oito relações entre $\mathrm{AB}$ e $\mathrm{AC}$ foram ensinadas por meio do procedimento de AMTS associado ao de exclusão; para as outras oito relações entre FG e FH foi utilizado o método de PO.

Também foram realizados dois testes de nomeação para os estímulos dos conjuntos B e G, e testes de equivalência para verificar se os participantes apresentavam desempenhos emergentes correspondentes à transitividade das relações $\mathrm{BC} / \mathrm{CB}$, e GH/HG. A seguir, o detalhamento de cada fase.

\section{Fase 2.1 - Procedimento de AMTS}

Esse procedimento, associado ao ensino por exclusão, foi utilizado nos dois grupos experimentais para o ensino das relações $\mathrm{AB}$ e AC. Em todos os blocos de ensino a apresentação do estímulo modelo foi simultânea à apresentação de três estímulos de comparação, sendo que o modelo era apresentado no centro da tela do notebook, e os comparações eram apresentados na parte inferior da tela, lado a lado. Nas tentativas auditivo-visuais, era apresentada a figura de um alto-falante no centro da tela e a palavra ditada era apresentada; após o participante tocar na figura do alto-falante, os estímulos de comparação eram apresentados. Nas tentativas visuais-visuais o mesmo acontecia, mas o modelo visual era apresentado em vez da figura do alto-falante.

No primeiro bloco foram ensinadas as relações auditivo-visuais (nome-face) A1B1 e A2B2, em um total de 12 tentativas. Nas seis primeiras, o estímulo modelo foi A1, e os estímulos de comparação foram B1, E1 e E2; nas seis tentativas seguintes, o estímulo modelo foi A2 e os de comparação foram B2, B1, e E1 ou E2. Na primeira 
tentativa, a pesquisadora pedia ao participante que escolhesse, diante do estímulo modelo, um dentre os três estímulos de comparação, a partir da seguinte instrução: "Primeiro você deverá tocar nesta imagem do alto-falante para ouvir um nome; em seguida, deverá tocar na foto da mulher que tem esse nome". Após cada resposta correta, o computador emitia um som "positivo" e a pesquisadora dizia: "Isso mesmo, você acertou!", ou frases semelhantes a essa; se a resposta do participante estivesse errada, o som emitido era “negativo" e a pesquisadora dizia: "Não está correto, vamos tentar novamente?". Tanto nos casos de acerto quanto nos de erro, a tentativa não era repetida, e era apresentada a tentativa seguinte. $\mathrm{O}$ intervalo entre as tentativas era de 2 segundos. $\mathrm{O}$ critério para passar para o próximo bloco era de 83,3\%, que corresponde a, no máximo, dois erros. Se o participante errasse três ou mais vezes, o bloco era repetido.

Em cada tentativa desse bloco e também dos demais, a ordem de apresentação dos estímulos de comparação era diferente da anterior, e a apresentação dos estímulos modelos era aleatória.

O bloco 2 consistiu em uma Linha de Base Reforçada (LBR) para as relações A1B1 e A2B2, com quatro tentativas para cada relação. A ordem de apresentação dos modelos era aleatória, com não mais que duas apresentações consecutivas de cada estímulo. A posição dos comparações e a posição do comparação correspondente ao modelo foram balanceadas entre as tentativas. Os estímulos de comparação foram B1 e B2, sendo que os estímulos conhecidos já não apareciam mais. As respostas dos participantes também foram consequenciadas diferencialmente para acertos e erros, como no bloco 1 . O critério de aprendizagem foi de $87,5 \%$ de acertos (1 erro no máximo). Se o participante não atingisse esse critério, voltaria ao bloco de ensino anterior.

No terceiro bloco foram ensinadas as relações A3B3 e A4B4, da mesma forma e com os mesmos critérios e número de tentativas do bloco 1; em seguida, era apresentado 
um bloco de LBR (bloco 4) para as relações A3B3/A4B4, como no bloco 2. Se o participante não atingisse $87,5 \%$ de acertos, voltaria ao bloco 3 .

O quinto bloco consistiu em uma Linha de Base Cheia Reforçada (LBCR), cujo objetivo foi fortalecer a aprendizagem de todas as relações $\mathrm{AB}$ ensinadas. O bloco 5 tinha 20 tentativas (cinco para cada relação ensinada). A ordem de apresentação de cada estímulo modelo (A1, A2, A3 ou A4) foi aleatória, assim como a posição em que três estímulos de comparação (Conjunto B) apareciam na tela do notebook. Nesse bloco os estímulos do conjunto $\mathrm{E}$ também não foram mais apresentados como comparações, apenas os do conjunto B. Todas as tentativas foram consequenciadas diferencialmente, e o critério de passagem para o bloco seguinte foi de $80 \%$ de acertos (máximo de quatro erros no bloco, mas não mais que dois erros para uma mesma relação). Caso o participante não atingisse esse critério, voltaria para o início do procedimento (bloco 1).

Em seguida foi apresentado um bloco (bloco 6) de Linha de Base Cheia em Extinção (LBCE), com apenas uma diferença em relação ao bloco anterior: respostas corretas e incorretas não foram consequenciadas diferencialmente. Para isso, antes do início desse bloco foi dada a seguinte instrução: “A partir de agora você não irá saber se acertou ou errou, mas continue se esforçando para acertar sempre!". O critério de desempenho estabelecido para este bloco foi de $80 \%$ de acertos, caso contrário o participante voltaria ao bloco anterior de LBCR.

Esses mesmos procedimentos foram empregados para o ensino e teste das relações AC (como descrito na Tabela 3). Atingido o critério de desempenho na LBCE para as relações $\mathrm{AC}$, era apresentado um bloco de 32 tentativas das relações $\mathrm{AB}$ e $\mathrm{AC}$ (quatro tentativas para cada relação), com critério de desempenho de $84,4 \%$ de acertos no bloco (máximo de 5 erros, sendo que não mais que dois para uma mesma relação). 
Nos blocos 14 e 16 foram realizados testes de nomeação para verificar se o participante que aprendeu as relações $\mathrm{AB}$ e $\mathrm{AC}$ também iria apresentar o comportamento de nomear as mulheres das fotos (um bloco antes dos testes de equivalência, e outro depois). O procedimento desse teste foi o mesmo empregado na Fase 1. Foram apresentadas quatro tentativas para cada estímulo do Conjunto B, em ordem aleatória, com a seguinte pergunta: “Qual é o nome dela?". Não houve critério de desempenho para esses blocos.

Entre os testes de nomeação foram realizados testes de equivalência para as relações emergentes BC e CB. Esse bloco (Bloco 15) foi subdividido em quatro partes, com dez tentativas em cada uma, totalizando 20 tentativas para a relação BC e 20 para CB. O formato desses testes foi o mesmo utilizado nos blocos anteriores, com apresentação simultânea do estímulo modelo e dos três estímulos de comparação. A Tabela 3 apresenta a sequência dos blocos de ensino e teste da Fase 2 do procedimento de AMTS, bem como suas características mais importantes. 
Tabela 3.

Sequência de Procedimentos de Ensino das Relações AB e AC, Testes de Nomeação, e Testes de Equivalência

\begin{tabular}{|c|c|c|c|c|c|}
\hline Procedimento & Relação & Modelo & Comparações & Bloco & Tentativas \\
\hline \multirow[t]{2}{*}{ Ensino AMTS } & A1B1 & $\mathrm{A} 1$ & B1 D1 D2 & 1 & 6 \\
\hline & $\mathrm{A} 2 \mathrm{~B} 2$ & $\mathrm{~A} 2$ & $\mathrm{~B} 2 \mathrm{~B} 1 \mathrm{D} 1 / \mathrm{D} 2 *$ & & 6 \\
\hline LBR & $\mathrm{A} 1 \mathrm{~B} 1 / \mathrm{A} 2 \mathrm{~B} 2$ & $\mathrm{~A} 1 / \mathrm{A} 2 *$ & B1 B2 & 2 & 8 \\
\hline \multirow[t]{2}{*}{ Ensino AMTS } & A3B3 & $\mathrm{A} 3$ & B3 D1 D2 & 3 & 6 \\
\hline & A4B4 & A4 & B4 B3 D1/D2 & & 6 \\
\hline LBR & A3B3/A4B4 & $\mathrm{A} 3 / \mathrm{A} 4$ & B3 B4 & 4 & 8 \\
\hline LBCR & $\mathrm{AB}$ & A1/A2/A3/A4 & B1 B2 B3 B4 & 5 & 20 \\
\hline LBCE & $\mathrm{AB}$ & A1/A2/A3/A4 & B1 B2 B3 B4 & 6 & 20 \\
\hline \multirow[t]{2}{*}{ Ensino AMTS } & $\mathrm{A} 1 \mathrm{C} 1$ & A1 & C1 E1 E2 & 7 & 6 \\
\hline & $\mathrm{A} 2 \mathrm{C} 2$ & A2 & C2 C1 E1/E2 & & 6 \\
\hline LBR & $\mathrm{A} 1 \mathrm{C} 1 / \mathrm{A} 2 \mathrm{C} 2$ & A1/A2 & $\mathrm{C} 1 \mathrm{C} 2$ & 8 & 8 \\
\hline \multirow[t]{2}{*}{ Ensino AMTS } & $\mathrm{A} 3 \mathrm{C} 3$ & $\mathrm{~A} 3$ & C3 E1 E2 & 9 & 6 \\
\hline & $\mathrm{A} 4 \mathrm{C} 4$ & A4 & C4 C3 E1/E2 & & 6 \\
\hline LBR & $\mathrm{A} 3 \mathrm{C} 3 / \mathrm{A} 4 \mathrm{C} 4$ & $\mathrm{~A} 3 / \mathrm{A} 4$ & $\mathrm{C} 3 \mathrm{C} 4$ & 10 & 8 \\
\hline LBCR & $\mathrm{AC}$ & A1/A2/A3/A4 & $\mathrm{C} 1 \mathrm{C} 2 \mathrm{C} 3 \mathrm{C} 4$ & 11 & 20 \\
\hline LBCE & $\mathrm{AC}$ & A1/A2/A3/A4 & $\mathrm{C} 1 \mathrm{C} 2 \mathrm{C} 3 \mathrm{C} 4$ & 12 & 20 \\
\hline \multirow[t]{2}{*}{ LBCE } & $\mathrm{AB} / \mathrm{AC}$ & A1/A2/A3/A4 & B1 B2 B3 B4 & 13 & 32 \\
\hline & & & $\mathrm{C} 1 \mathrm{C} 2 \mathrm{C} 3 \mathrm{C} 4$ & & \\
\hline Teste de Nomeação & & $\mathrm{B} 1 / \mathrm{B} 2 / \mathrm{B} 3 / \mathrm{B} 4$ & & 14 & 16 \\
\hline \multirow[t]{2}{*}{ Teste Equivalência } & $\mathrm{BC}$ & $\mathrm{B} 1 / \mathrm{B} 2 / \mathrm{B} 3 / \mathrm{B} 4$ & $\mathrm{C} 1 \mathrm{C} 2 \mathrm{C} 3 \mathrm{C} 4$ & 15 & 20 \\
\hline & $\mathrm{CB}$ & $\mathrm{C} 1 / \mathrm{C} 2 / \mathrm{C} 3 / \mathrm{C} 4$ & B1 B2 B3 B4 & & 20 \\
\hline Teste de Nomeação & & $\mathrm{B} 1 / \mathrm{B} 2 / \mathrm{B} 3 / \mathrm{B} 4$ & & 16 & 16 \\
\hline
\end{tabular}

*As barras (/) indicam que, entre os estímulos do conjunto, apenas um era apresentado em cada tentativa 


\section{Fase 2.2 - Procedimento PO}

As relações FG e FH também foram ensinadas para todos os participantes, com o mesmo número de blocos que o procedimento de AMTS, por meio do procedimento de PO. Nos blocos de ensino de cada relação FG e FH, o estímulo modelo (nome ditado) foi apresentado seis vezes consecutivas, da seguinte forma: ao mesmo tempo em que era apresentado, individualmente, cada estímulo visual (face ou nome escrito) no centro da tela do notebook, o nome ditado correspondente era apresentado ao longo de seis afirmações (ver Tabela 4). Dessa forma, o participante era exposto a um evento ostensivo que pareava um estímulo verbal com um estímulo visual, pois, enquanto olhava para a foto de uma mulher desconhecida, o participante também ouvia seu nome por seis vezes.

Essas frases foram previamente gravadas pela pesquisadora para garantir a mesma entonação, velocidade, e duração para todos os participantes. A Tabela 4 apresenta as frases utilizadas na PO para cada estímulo (foto - conjunto G; ou nome escrito - conjunto $\mathrm{H})$.

Tabela 4.

Estrutura das Frases Utilizadas para o Ensino das Relações FG e GH

\begin{tabular}{cc}
\hline Ensino das Relações FG & Ensino das Relações FH \\
\hline $1-$ Beatriz. & $1-$ Beatriz. \\
2 - Essa é a Beatriz. & $2-$ Esse é o nome da Beatriz. \\
3 - A Beatriz está sorrindo. & $3-$ Está escrito Beatriz. \\
$4-$ Beatriz tem cabelo curto. & $4-$ Beatriz escreve assim. \\
$5-$ Essa é a foto da Beatriz. & $5-$ O computador mostra o nome da Beatriz. \\
$6-$ Vou repetir: Beatriz. & $6-$ Vou repetir: Beatriz. \\
\hline
\end{tabular}

No bloco 1 foram ensinadas as relações F1G1 e F2G2, com um total de 12 tentativas; nas seis primeiras foi realizado o pareamento ostensivo do estímulo verbal F1 
com o estímulo visual G1; nas seis tentativas seguintes foi realizado o pareamento do estímulo verbal F2 com o estímulo visual G2. Em seguida (bloco 2) foi realizado um bloco de tentativas consequenciadas com essas relações pelo procedimento de matchingto-sample, com quatro tentativas para cada relação ensinada. Assim como no bloco 2 do procedimento de AMTS, o estímulo modelo foi F1 ou F2, e os estímulos de comparação G1 e G2. A instrução dada pela pesquisadora também foi a mesma: "Toque na figura do auto-falante e ouça o nome; depois toque na foto da mulher com esse nome". Respostas corretas e incorretas foram consequenciadas diferencialmente, e o critério de desempenho foi o mesmo (87,5\% de acertos); se o participante não o atingisse, voltaria para a exposição do bloco 1 .

Os mesmos procedimentos foram utilizados nos blocos 3 e 4 , para o ensino das relações F3G3 e F4G4.

No bloco 5 foi realizado um bloco de exposição ao PO para todas as relações FG ensinadas, com um pareamento para cada relação (i.e., cada foto foi apresentada uma única vez, no centro da tela, simultaneamente com uma frase em que o nome da mulher da foto era apresentado). Logo em seguida, foi apresentada um bloco de LBCE para as relações FG, como no bloco 6 do AMTS: foram apresentadas cinco tentativas para cada relação, em um total de 20 tentativas, com o critério de desempenho de $80 \%$ de respostas corretas. Se o participante não atingisse esse critério, voltaria para o ensino do bloco 5.

Os mesmos procedimentos forma empregados para o ensino das relações $\mathrm{FH}$ (relações entre nome ditado e nome escrito - ver Tabela 5). Da mesma forma, se o participante não atingisse o critério de acertos nos testes de aprendizagem (blocos 8, 10 e 12), voltaria para o bloco de ensino correspondente. Após o ensino das relações FG e FH, os participantes eram expostos a um bloco de LBCE (bloco 13, dividido em 13A e 13B 
com 20 tentativas em cada) para essas relações. Se o participante não atingisse o critério de $84,4 \%$ de acertos, voltaria para o(s) bloco(s) de ensino das relações que não acertou.

Da mesma forma como ocorria no ensino por AMTS, nos blocos 14 e 16 foram realizados testes de nomeação das faces com quatro tentativas para cada foto, em ordem aleatória, com a seguinte pergunta feita pela pesquisadora: “Qual é o nome dela?”. Não houve critério de desempenho para esses blocos. Também foi realizado um teste de equivalência entre os testes de nomeação, para testar as relações emergentes GH e HG, com a mesma estrutura empregada no AMTS. 
Tabela 5.

Sequência de Procedimentos de Ensino das Relações FG e FH, Testes de Nomeação e Teste de Equivalência.

\begin{tabular}{|c|c|c|c|c|c|}
\hline Procedimento & Relação & Modelo & Comparações & Bloco & Tentativas \\
\hline \multirow[t]{2}{*}{ Ensino PO } & F1G1 & & & 1 & 6 \\
\hline & $\mathrm{F} 2 \mathrm{G} 2$ & & & & 6 \\
\hline \multirow{2}{*}{$\begin{array}{c}\text { Teste de } \\
\text { Reconhecimento }\end{array}$} & F1G1 & $\mathrm{F} 1$ & G1 G2 & 2 & 4 \\
\hline & $\mathrm{F} 2 \mathrm{G} 2$ & $\mathrm{~F} 2$ & G1 G2 & & 4 \\
\hline \multirow[t]{2}{*}{ Ensino PO } & F3G3 & & & 3 & 6 \\
\hline & F4G4 & & & & 6 \\
\hline \multirow{2}{*}{$\begin{array}{c}\text { Teste de } \\
\text { Reconhecimento }\end{array}$} & F3G3 & F3 & G3 G4 & 4 & 4 \\
\hline & F4G4 & $\mathrm{F} 4$ & G3 G4 & & 4 \\
\hline \multirow[t]{4}{*}{ Ensino PO completo } & F1G1 & & & 5 & 5 \\
\hline & $\mathrm{F} 2 \mathrm{G} 2$ & & & & 5 \\
\hline & F3G3 & & & & 5 \\
\hline & F4G4 & & & & 5 \\
\hline LBCE & FG & $\mathrm{F} 1 / \mathrm{F} 2 / \mathrm{F} 3 / \mathrm{F} 4$ & G1 G2 G3 G4 & 6 & 20 \\
\hline \multirow[t]{2}{*}{ Ensino PO } & F1H1 & & & 7 & 6 \\
\hline & $\mathrm{F} 2 \mathrm{H} 2$ & & & & 6 \\
\hline \multirow{2}{*}{$\begin{array}{c}\text { Teste de } \\
\text { Reconhecimento }\end{array}$} & F1H1 & $\mathrm{F} 1$ & G1 G2 & 8 & 4 \\
\hline & $\mathrm{F} 2 \mathrm{H} 2$ & $\mathrm{~F} 2$ & G1 G2 & & 4 \\
\hline \multirow[t]{2}{*}{ Ensino PO } & $\mathrm{F} 3 \mathrm{H} 3$ & & & 9 & 6 \\
\hline & $\mathrm{F} 4 \mathrm{H} 4$ & & & & 6 \\
\hline \multirow{2}{*}{$\begin{array}{c}\text { Teste de } \\
\text { Reconhecimento }\end{array}$} & $\mathrm{F} 3 \mathrm{H} 3$ & F3 & G3 G4 & 10 & 4 \\
\hline & $\mathrm{F} 4 \mathrm{H} 4$ & $\mathrm{~F} 4$ & G3 G4 & & 4 \\
\hline \multirow[t]{4}{*}{ Ensino PO completo } & F1H1 & & & 11 & 6 \\
\hline & $\mathrm{F} 2 \mathrm{H} 2$ & & & & 6 \\
\hline & $\mathrm{F} 3 \mathrm{H} 3$ & & & & 6 \\
\hline & F4H4 & & & & 6 \\
\hline LBCE & FH & $\mathrm{F} 1 / \mathrm{F} 2 / \mathrm{F} 3 / \mathrm{F} 4$ & G1 G2 G3 G4 & 12 & 20 \\
\hline \multirow[t]{2}{*}{ LBCE } & FG/FH & $\mathrm{F} 1 / \mathrm{F} 2 / \mathrm{F} 3 / \mathrm{F} 4$ & G1 G2 G3 G4 & 13 & 32 \\
\hline & & & H1 H2 H3 H4 & & \\
\hline Teste de Nomeação & & $\mathrm{G} 1 / \mathrm{G} 2 / \mathrm{G} 3 / \mathrm{G} 4$ & & 14 & 16 \\
\hline \multirow{2}{*}{$\begin{array}{c}\text { Teste de } \\
\text { Equivalência }\end{array}$} & $\mathrm{GH}$ & G1/G2/G3/G4 & H1 H2 H3 H4 & 15 & 20 \\
\hline & $\mathrm{HG}$ & $\mathrm{H} 1 / \mathrm{H} 2 / \mathrm{H} 3 / \mathrm{H} 4$ & G1 G2 G3 G4 & & 20 \\
\hline Teste de Nomeação & & $\mathrm{G} 1 / \mathrm{G} 2 / \mathrm{G} 3 / \mathrm{G} 4$ & & 16 & 16 \\
\hline
\end{tabular}




\section{Fase 3 - Pós-Teste}

Todos os participantes foram expostos a essa fase, cujo objetivo foi avaliar o efeito de cada procedimento de ensino sobre a manutenção das relações aprendidas. O pós-teste foi aplicado individualmente com cada participante, uma semana após o término dos dois procedimentos de ensino.

\section{Fase 3.1 - Teste de Manutenção das relações AB, AC, BC e CB}

O método utilizado para testar a manutenção da aprendizagem foi o AMTS, no mesmo formato das fases anteriores. A ordem de apresentação de cada estímulo modelo foi aleatória (A1, A2, A3, A4, para as relações diretamente ensinadas; B1, B2, B3, B4, $\mathrm{C} 1, \mathrm{C} 2, \mathrm{C} 3, \mathrm{C} 4$, para as relações transitivas emergentes), realizada por sorteio antes da edição das tarefas no programa Jclic. Os estímulos de comparação (B1, B2, B3, B4, C1, C2, C3, C4) foram apresentados abaixo do modelo, de forma simultânea e em ordem aleatória, sendo três estímulos de comparação para cada tentativa. Foram apresentadas quatro tentativas para cada relação testada, em um total de 64 tentativas. Não havia consequências diferenciais para acertos e erros nessas tentativas.

\section{Fase 3.2 - Teste de Manutenção das Relações FG, FH, GH e HG}

Para testar a manutenção da aprendizagem dessas relações, o procedimento foi idêntico ao da fase 3.1 (tentativas de MTS sem consequências diferenciais para acertos e erros), apenas com a diferença dos estímulos utilizados, que eram dos conjuntos $\mathrm{F}$, G e H.

\section{Fase 3.3 - Teste de Manutenção do Desempenho de Nomeação}

Todos os participantes repetiram o teste de nomeação das faces, da mesma forma como realizado no Bloco 14 de cada procedimento de ensino. 


\section{RESULTADOS}

Inicialmente analisou-se o desempenho dos participantes na fase de aprendizagem das relações nome ditado-face, nos dois procedimentos de ensino. A Figura 1 apresenta a porcentagem média de acertos do conjunto de participantes, independente do grupo experimental, em cada bloco de ensino ou teste de relações nome ditado-face (AB ou FG) nos procedimentos de AMTS e PO.

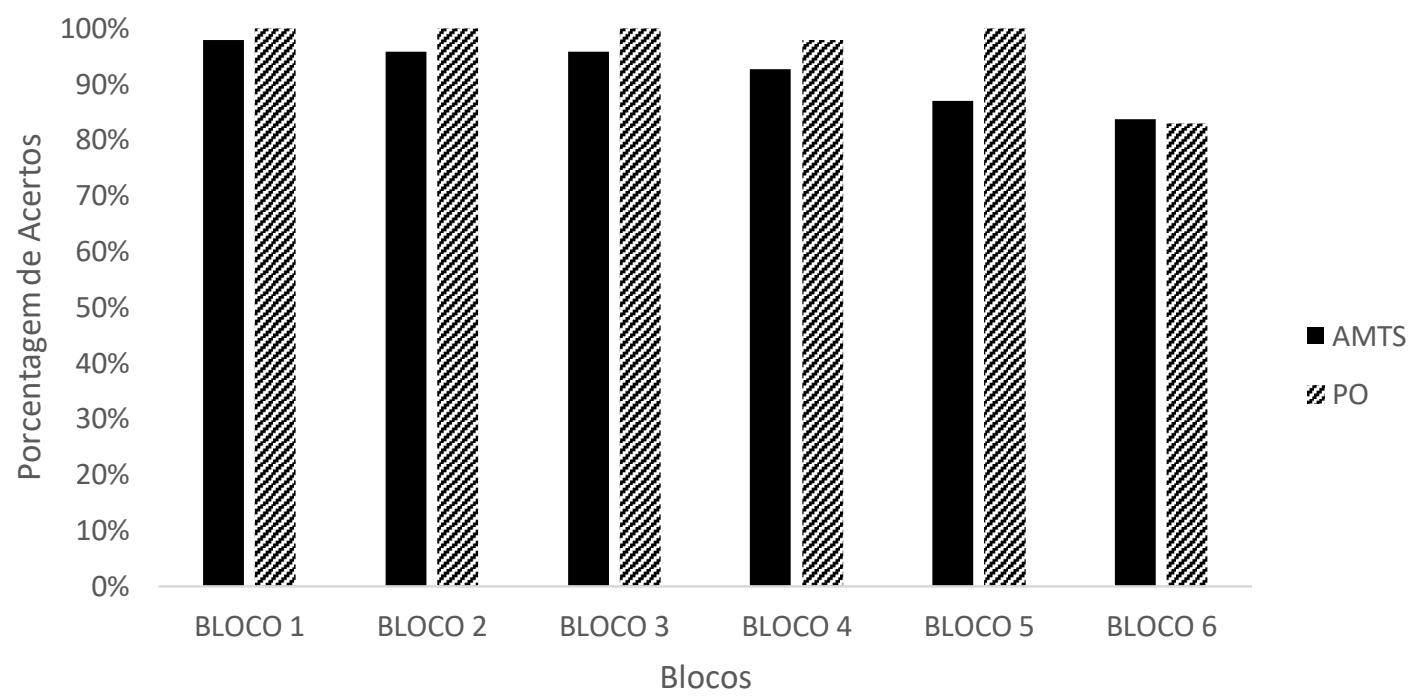

Figura 1. Porcentagem média de acertos dos participantes na aprendizagem das relações nome-face por AMTS e PO.

De modo geral, observa-se que a porcentagem média de acertos dos participantes nos blocos de ensino 1 a 4 é ligeiramente superior no procedimento de PO. Nos dois procedimentos, porém, observa-se desempenho médio superior a $90 \%$ de acertos. No bloco 5, o desempenho médio dos participantes é superior no PO (cerca de $87 \%$ em AMTS e 100\% em PO). No bloco 6, em que foram testadas todas as relações previamente ensinadas sem o reforço diferencial, a porcentagem média de acertos nos dois procedimentos de ensino foi semelhante (83,7\% em AMTS e 82,9\% em PO), mas inferior aos outros blocos. 
A Tabela 6 apresenta o número de repetições de bloco de ensino das relações nome ditado-face $(\mathrm{AB}$ ou $\mathrm{FG})$ necessárias para cada participante atingir o critério de aprendizagem proposto.

Tabela 6.

Número de Repetição de Blocos Para a Aquisição das Relações Nome-Face por AMTS e $P O$

\begin{tabular}{|c|c|c|c|c|c|c|c|c|c|c|c|c|}
\hline & \multicolumn{2}{|c|}{ BLOCO 1} & \multicolumn{2}{|c|}{ BLOCO 2} & \multicolumn{2}{|c|}{ BLOCO 3} & \multicolumn{2}{|c|}{ BLOCO 4} & \multicolumn{2}{|c|}{ BLOCO 5} & \multicolumn{2}{|c|}{ BLOCO 6} \\
\hline & AMTS & $\mathrm{PO}$ & AMTS & $\mathrm{PO}$ & AMTS & $\mathrm{PO}$ & AMTS & $\mathrm{PO}$ & AMTS & $\mathrm{PO}$ & AMTS & $\mathrm{PO}$ \\
\hline P1 & - & - & - & - & - & - & - & - & - & - & - & - \\
\hline P2 & - & - & - & - & - & - & - & - & - & - & - & - \\
\hline P3 & - & - & - & - & - & - & - & - & - & - & - & - \\
\hline P4 & - & - & - & - & - & - & - & - & - & - & - & - \\
\hline P5 & - & - & - & - & - & - & - & - & - & - & - & - \\
\hline P6 & - & - & - & - & - & - & - & - & - & - & - & - \\
\hline P7 & - & - & - & - & - & - & - & - & - & - & - & - \\
\hline P8 & 1 & - & 1 & - & 1 & - & 1 & - & 1 & - & 1 & - \\
\hline P9 & - & - & - & - & - & - & 1 & - & - & 1 & 1 & 1 \\
\hline P10 & - & - & - & - & - & - & - & - & - & 1 & - & 1 \\
\hline P11 & 1 & - & 1 & - & 1 & - & - & - & 2 & 2 & 2 & 2 \\
\hline P12 & - & - & - & - & - & - & - & - & - & 1 & - & 1 \\
\hline
\end{tabular}

Nota: (-) indica que não houve repetição de blocos.

Na Tabela 6 observa-se que não houve necessidade de repetição dos blocos de ensino e teste de nenhum dos procedimentos para os participantes 1 a 7 (os de maior escolaridade). Os participantes P10 e P12, que tinham quatro e 11 anos de escolaridade respectivamente, somente precisaram repetir os blocos 5 e 6 no procedimento de PO (blocos em que todas as relações ensinadas eram apresentadas juntas). Os participantes 8, 9 e 11, porém, precisaram de mais repetições de bloco. P8 precisou de uma repetição de todos os blocos de ensino no procedimento de AMTS. P9 precisou repetir os blocos 4 e 6 em AMTS e os blocos 5 e 6 em PO. O participante P11 foi o que precisou do maior número de repetições de blocos: no procedimento de AMTS, repetiu uma vez os blocos 1, 2 e 3 e duas vezes os blocos 5 e 6; no procedimento de PO repetiu duas vezes os blocos 5 e 6. Observa-se, portanto, que os participantes com maior escolaridade (exceto P12) não repetiram os blocos de ensino em nenhum dos procedimentos. Os participantes de 
menor escolaridade, por sua vez, precisaram de repetições, especialmente no procedimento de AMTS.

Se forem computadas as repetições de bloco por procedimento, observa-se que em AMTS foram realizadas 15 repetições, enquanto que em PO foram realizadas 10 repetições. Os blocos com maior número de repetições foram os blocos 5 e 6 , com, respectivamente, oito e nove repetições (no bloco 5, três repetições em AMTS e cinco em PO; no bloco 6, quatro repetições em AMTS e cinco em PO). A maior dificuldade dos dois procedimentos, portanto, ocorreu em relação aos blocos de ensino e teste que apresentavam todas as relações juntas, independentemente do procedimento de ensino ou de haver ou não consequências diferenciais para o desempenho dos participantes.

Com relação ao desempenho dos participantes na aquisição das relações nome ditado-nome escrito ( $\mathrm{AC}$ e $\mathrm{FH}$ ), todos apresentaram 100\% de acertos nos blocos de ensino e teste dos procedimentos de AMTS e PO. Este resultado provavelmente deve-se ao fato de que todos os participantes foram capazes de ouvir os nomes das mulheres desconhecidas (conjuntos A e F), e pareá-los aos seus respectivos nomes escritos (conjuntos $\mathrm{C}$ e $\mathrm{H}$ ). Não se tratou, portanto, de um conjunto de blocos de ensino e testes propriamente ditos, pois esse tipo de tarefa já fazia parte do repertório de habilidades dos 12 participantes.

A Figura 2 apresenta a porcentagem média de acertos dos participantes no bloco 13 (linha de base cheia em extinção para todas as relações ensinadas: AB e AC no AMTS; FG e FH no PO), logo após o ensino e na fase de manutenção. Além disso, a Figura 2 também apresenta a porcentagem média de acertos dos participantes nos testes de transitividade/equivalência, logo após a conclusão de cada procedimento de ensino e na fase de manutenção (uma semana após o término de cada procedimento). 


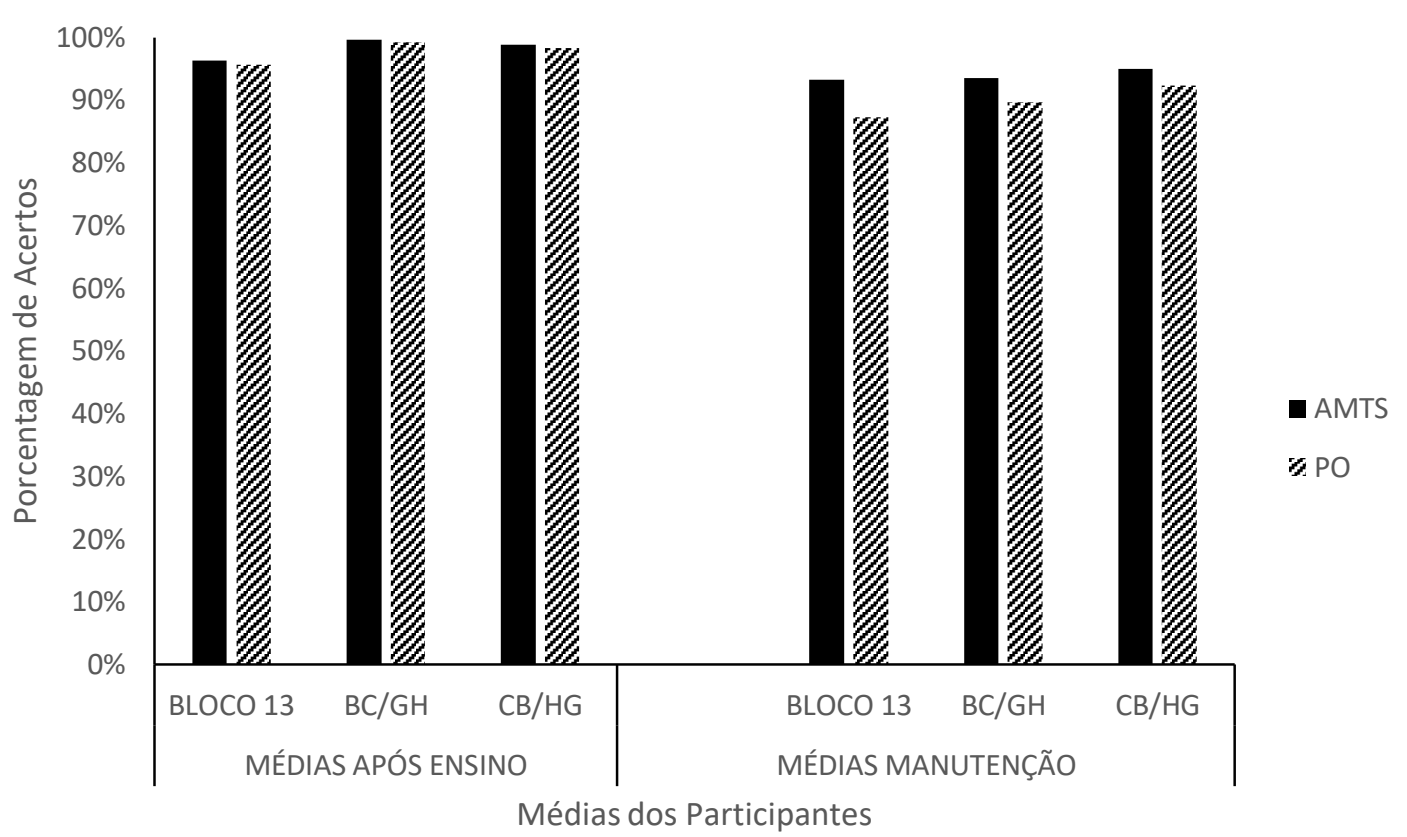

Figura 2. Médias das porcentagens de acertos dos participantes no Bloco 13 e nos testes de Equivalência (BC/GH e $\mathrm{CB} / \mathrm{HG})$ logo após o procedimento de ensino e após uma semana (manutenção).

De modo geral pode-se observar que no bloco 13, em ambos os procedimentos, os participantes mantiveram média de acertos superior a 90\% logo após a conclusão de cada procedimento, e apresentaram a emergência de relações transitivas (equivalência) também a partir dos dois procedimentos. Na fase de manutenção, a porcentagem média de acertos no bloco 13 no AMTS continuou acima de 90\%, porém, para as relações aprendidas por PO ficou um pouco abaixo, com $87,23 \%$ de acertos. Nos testes de equivalência realizados na fase de manutenção, observa-se uma discreta diminuição na porcentagem de acertos em relação à fase pós-ensino: em AMTS, essa diminuição foi de 6,04\% nas relações $\mathrm{BC}$ e 3,75\% nas relações $\mathrm{CB}$; em $\mathrm{PO}, 9,58 \%$ nas relações $\mathrm{GH}$, e 6,04\% nas relações HG. Não se pode afirmar, entretanto, que essas reduções em ambos os procedimentos na fase de manutenção sejam significativas; apenas que há indicativos de um eventual enfraquecimento das relações em função da passagem do tempo. 
A Figura 3 apresenta os dados individuais dos participantes com maior escolaridade nos testes de nomeação das fotos. N1 refere-se ao teste realizado logo após a conclusão do procedimento de ensino (bloco 14); N2, ao teste de nomeação realizado após os testes de equivalência (bloco 16) e N3 refere-se ao teste de nomeação das fotos realizado na fase de manutenção.

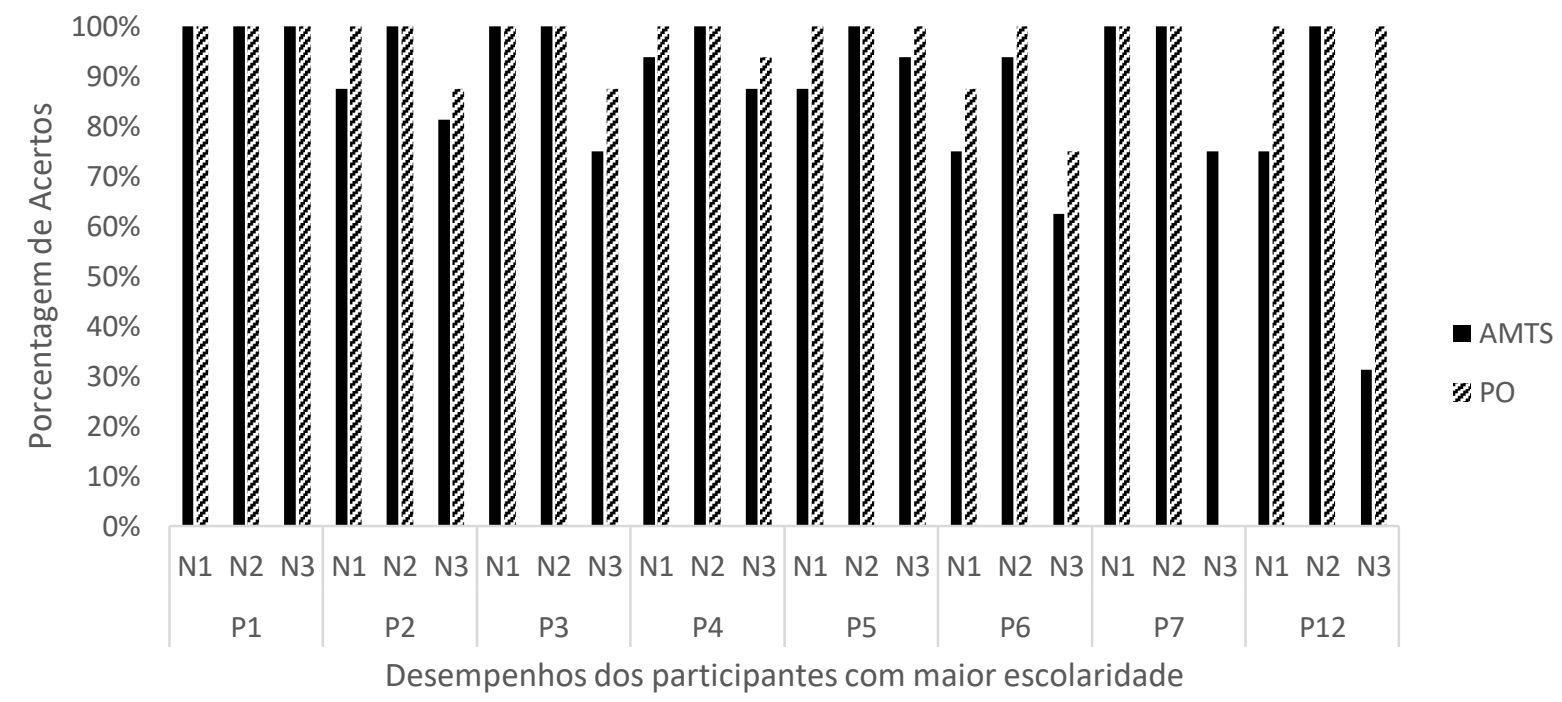

Figura 3. Porcentagem de acertos dos participantes com ensino médio ou superior nos três testes de nomeação.

Observa-se na Figura 3 que P1 foi a única participante que nomeou corretamente todas as fotos em todos os testes de nomeação. O padrão de desempenho dos demais participantes foi mais variável, mas é possível observar alguns pontos em comum. O melhor desempenho em nomeação de todos os participantes ocorreu, nos dois procedimentos, em N2 (após os testes de equivalência). Com exceção de P6, todos os participantes apresentaram 100\% de nomeações corretas, tanto em AMTS quanto em PO. P6 apresentou 94\% de acertos em N2 no procedimento de AMTS.

Também de modo geral, o desempenho dos participantes foi pior em N3 (manutenção) na comparação com os outros dois testes de nomeação, indicando uma 
deterioração desse desempenho com a passagem do tempo. Essa deterioração, porém, foi maior para os estímulos aprendidos apenas pelo procedimento de AMTS, em comparação aos estímulos aprendidos por PO. Em média, os participantes acertaram 80\% das nomeações em N3 no procedimento de PO e 75\% no de AMTS. Excluindo-se os piores resultados de N3 nos dois procedimentos (31\% de P12 em AMTS e 0\% de P7 em PO), verifica-se uma média de acertos em N3 de 82\% em AMTS e de 92\% em PO. Isso significa que, com exceção de $\mathrm{P} 7$, todos os demais participantes obtiveram melhores resultados na nomeação das fotos na fase de manutenção após o procedimento de PO. O mesmo ocorreu em N1 (o teste de manutenção administrado logo após o término de cada procedimento de ensino): em média, verificou-se 90\% de acertos em AMTS e 98,5\% em PO.

Considerando as diferenças encontradas na fase de ensino entre participantes de maior e menor escolaridade, a Figura 4 apresenta os mesmos dados da Figura 3, mas em relação aos participantes com menor escolaridade (P8, P9, P10 e P11).

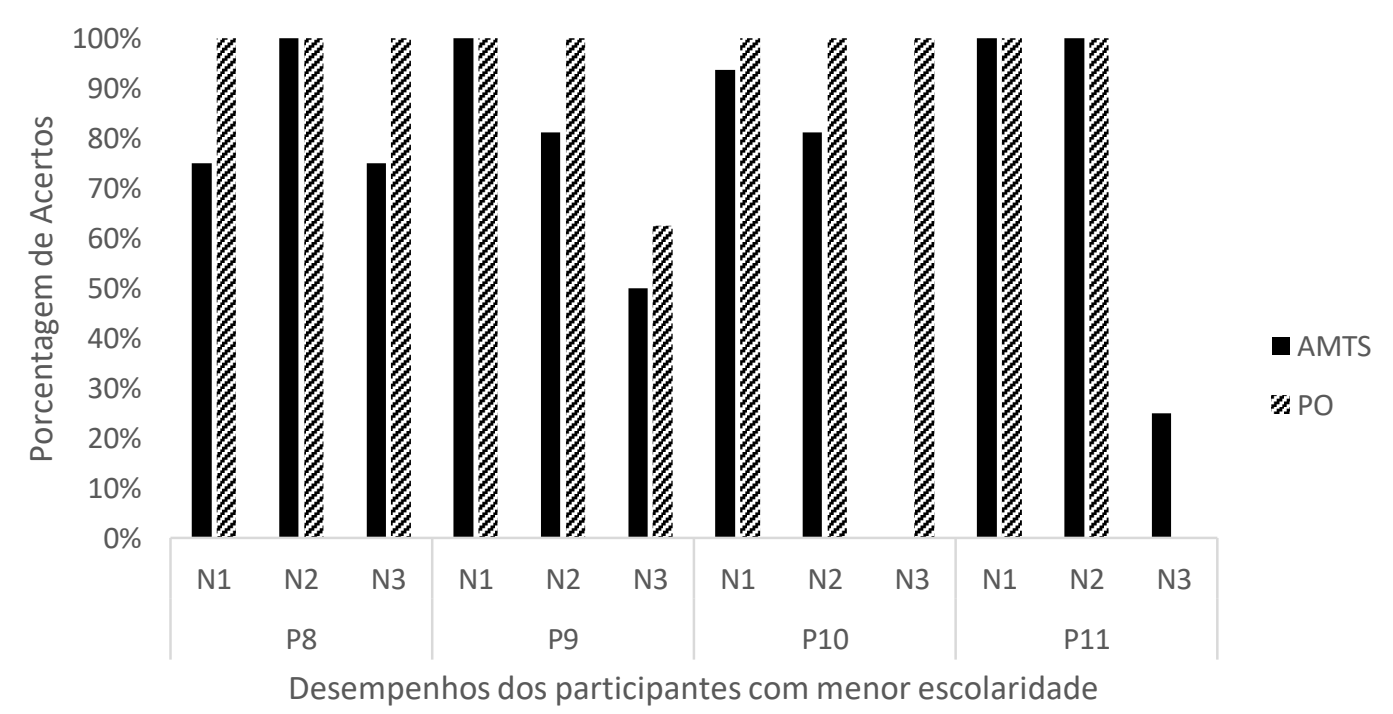

Figura 4. Porcentagem de acertos dos participantes com escolaridade inferior a oito anos nos três testes de nomeação. 
Em N1, o desempenho dos participantes de menor escolaridade também se mostrou melhor em PO do que em AMTS: em média, 92\% de acertos em AMTS e 100\% de acertos em PO, desempenho tão bom quanto o dos participantes de maior escolaridade. Assim como para os participantes de maior escolaridade, verificou-se que o melhor desempenho dos participantes de menor escolaridade ocorreu em N2, conduzido após os testes de equivalência. Com exceção de P9 e P10 no procedimento de AMTS, que obtiveram $81 \%$ de acertos, os demais participantes nomearam corretamente todas as fotos em todas as tentativas. Também como os participantes de maior escolaridade, o pior desempenho em nomeação ocorreu em N3 (manutenção). A deterioração observada no desempenho de nomeação desses participantes de menor escolaridade em N3, porém, foi maior do que a observada entre os participantes de maior escolaridade: em média, 37\% de acertos em AMTS e 65\% de acertos em PO. Nesse caso, o desempenho dos participantes após procedimento de PO também se mostrou, em média, melhor do que após AMTS.

A Figura 5 apresenta o desempenho médio dos participantes, agrupados em função da escolaridade, nos testes de equivalência e nomeação realizados logo após a fase de ensino e na fase de manutenção, apenas para o procedimento de AMTS. 


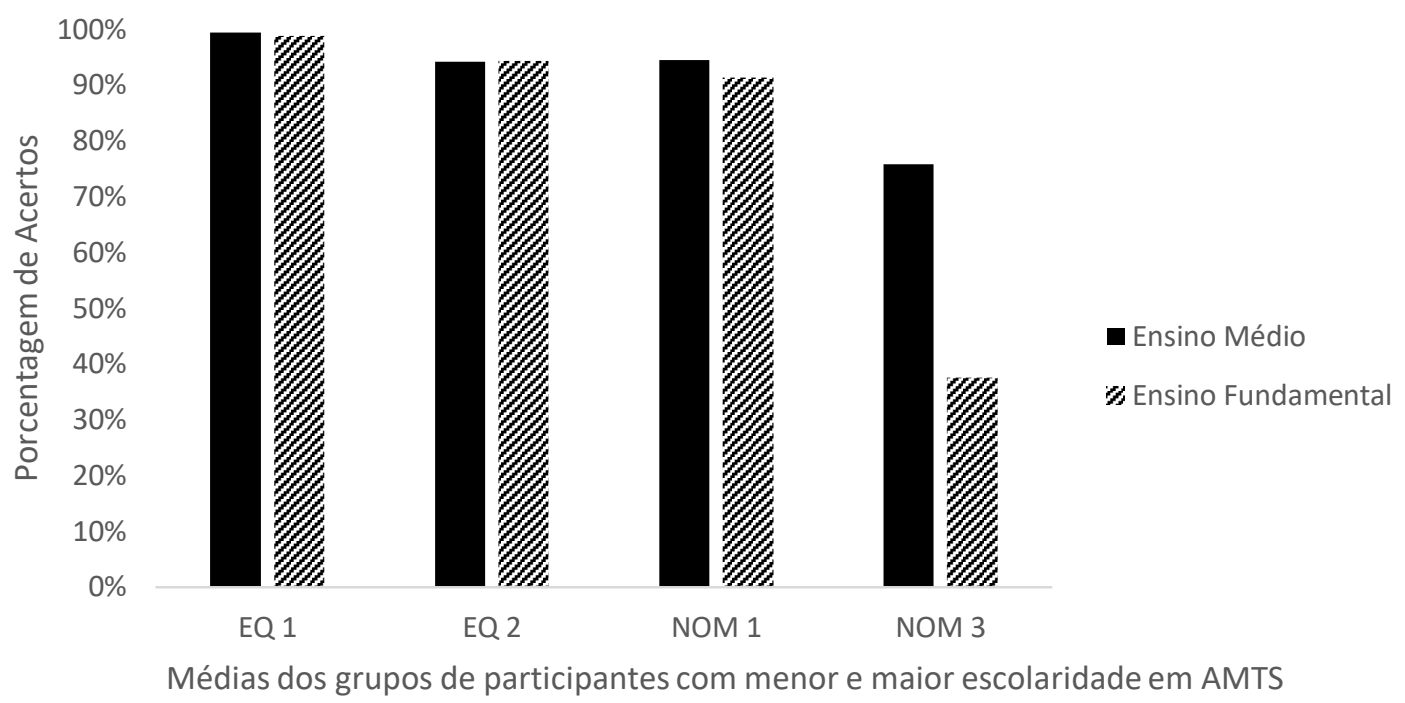

Figura 5. Porcentagem média de acertos dos participantes com escolaridade até o ensino fundamental (barras hachuradas), e dos participantes com escolaridade superior ou igual ao ensino médio (barras escuras), no procedimento de ensino AMTS. EQ 1: médias de acerto de cada grupo no teste de equivalência realizado logo após o ensino; EQ 2: médias no teste de equivalência realizado na fase de manutenção; NOM 1: médias dos dois testes de nomeação, para cada grupo, realizados após o ensino; NOM 3: médias no teste de nomeação na fase de manutenção.

Na Figura 5, observa-se que as médias de acertos dos dois grupos ficaram acima de $90 \%$ nos dois testes de equivalência, e no teste de nomeação realizado logo após o ensino. Nota-se uma queda de desempenho no teste de nomeação realizado uma semana após o ensino de AMTS, na fase de manutenção: o grupo com maior escolaridade apresentou uma média de acertos de 76\%, e o grupo com menor escolaridade obteve uma média de $38 \%$ de acertos. Em comparação às medias de acertos nos testes de nomeação realizados logo após o ensino, a queda foi de $19 \%$ para o grupo com maior escolaridade, e de 53\% para o grupo com escolaridade até o ensino fundamental.

Como já demonstrado nas Figuras 3 e 4, o desempenho dos dois grupos de participantes no procedimento de AMTS foi pior em N3 (manutenção), sendo que o grupo com menor porcentagem de acertos também foi o de menor escolaridade. 
A Figura 6 apresenta a porcentagem média de acertos dos participantes, agrupados por escolaridade, nos testes de equivalência e nomeação, após o procedimento de PO.

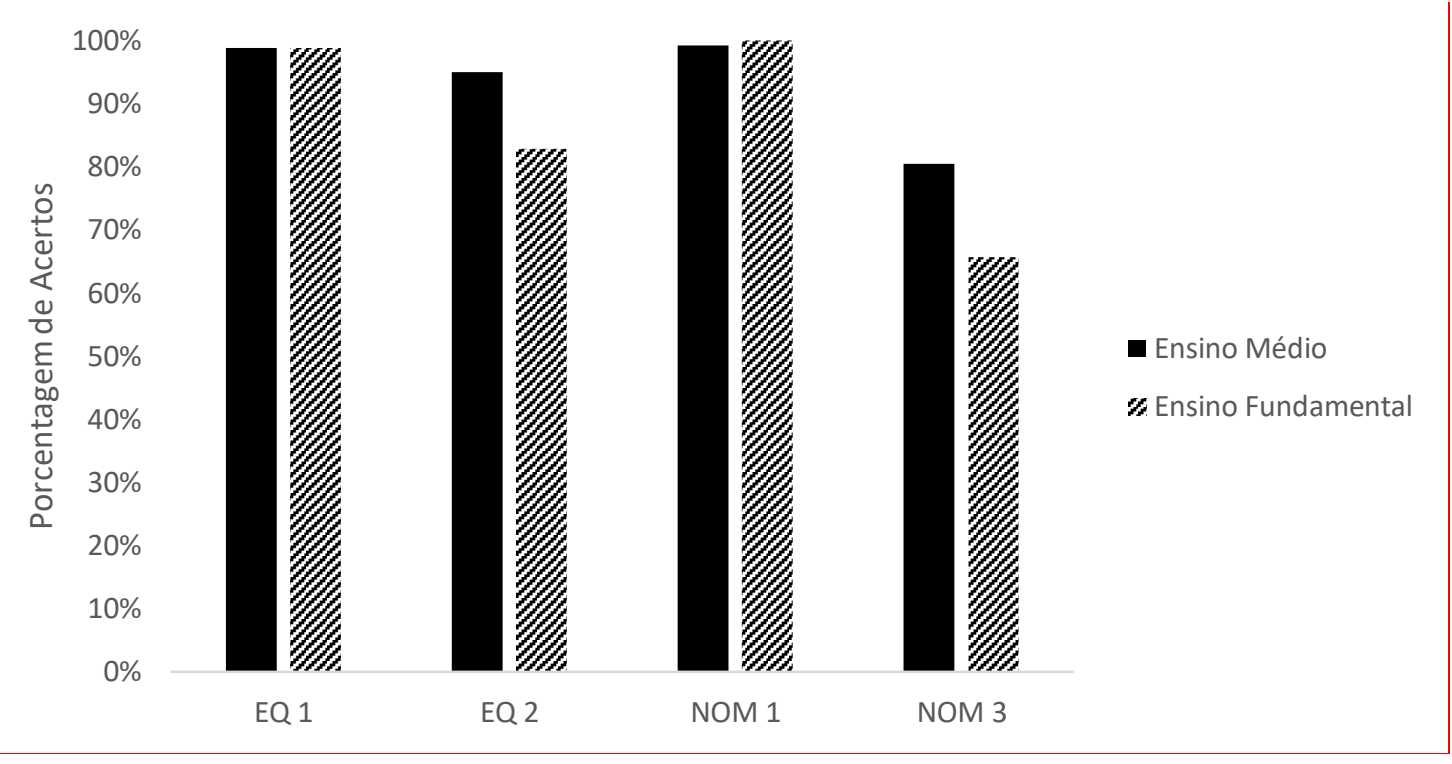

Figura 6. Médias dos desempenhos dos participantes com escolaridade até o ensino fundamental (menor escolaridade), e dos participantes com escolaridade superior ou igual ao ensino médio (maior escolaridade), após procedimento de ensino por PO.

Na Figura 6 é possível observar algumas diferenças no desempenho desses dois grupos em cada procedimento de ensino. Apesar de se verificar desempenhos semelhantes dos dois grupos no primeiro teste de equivalência (EQ 1), no segundo teste (EQ 2) o grupo de menor escolaridade apresentou porcentagem de acertos menor: $83 \%$ de acertos, contra 94\% de acertos do grupo mais escolarizado. O tamanho amostral pequeno, no entanto, não permite a verificação de diferença estatística entre esses resultados. Quando se analisa o desempenho dos dois grupos nos testes de nomeação, observa-se que no primeiro teste de nomeação, os dois grupos apresentam 100\% de acertos, mas essa porcentagem de acertos diminui no teste da fase de manutenção (NOM3): $80 \%$ no grupo de maior 
escolaridade e $66 \%$ no grupo menos escolarizado. Esses resultados, porém, são melhores que os obtidos após o procedimento de AMTS (ver Figura 5).

Esses resultados corroboram os dados apresentados nas Figuras 3 e 4: os dois grupos de participantes de diferentes níveis de escolaridade apresentaram pior desempenho no teste de nomeação em NOM3 (manutenção). Essa deterioração observada foi maior no grupo com menor escolaridade, e no procedimento de AMTS. 


\section{DISCUSSÃO}

O primeiro objetivo deste estudo foi comparar dois procedimentos para o ensino de relações arbitrárias entre nomes ditados, nomes escritos e faces, com participantes idosos sem queixa de dificuldades cognitivas (saudáveis). Em geral, não houve diferenças entre os dois procedimentos quanto ao desempenho dos participantes nas etapas de ensino das relações $\mathrm{AB}$ e FG. Observou-se apenas uma queda na média de acertos dos participantes no bloco 6 (Linha de Base cheia em extinção), em ambos os procedimentos de ensino, mas o desempenho dos participantes foi semelhante e todos atingiram o critério de acertos de $80 \%$, indicando a aprendizagem de todas as relações nome-face ensinadas.

Com a análise dos resultados demonstrados nos testes de manutenção (bloco 13 de cada procedimento), também é possível concluir que essa aprendizagem foi mantida para todas as relações ensinadas, em ambos os procedimentos: em AMTS a média de acertos continuou acima de $90 \%$, e no PO ficou em 87,23\%. Apesar dessa pequena diferença, não se pode afirmar que o procedimento de AMTS é mais eficaz que o PO na manutenção da aprendizagem. A ordem de aplicação dos procedimentos também não influenciou no desempenho apresentado pelos participantes.

Os resultados obtidos ao longo do ensino mostram que ambos os procedimentos foram eficientes em promover a aprendizagem das relações propostas e que, portanto, o PO não mostrou um efeito facilitador, como pensado inicialmente, mas também não dificultou a aprendizagem dessas mesmas relações. Considerando que a amostra de participantes foi constituída de idosos saudáveis, é possível pensar na aplicação do procedimento de PO para idosos com comprometimento cognitivo a fim de verificar se, para esses indivíduos, o PO apresenta algum efeito específico.

Tal efeito foi verificado por Fontanesi e Schmidt (2019) no ensino de relações condicionais arbitrárias auditivo-visuais para uma idosa com afasia decorrente de um 
acidente vascular encefálico. A idosa apresentou muitas dificuldades em atingir os critérios de desempenho estabelecidos em um procedimento de AMTS auditivo-visual quando eram apresentados, em um mesmo bloco de tentativas, quatro relações condicionais entre palavras ditadas e figuras não familiares, mesmo após a exposição massiva aos blocos de ensino. A introdução de um procedimento de PO antes do início das tentativas de AMTS em cada sessão favoreceu a aprendizagem dessa idosa, tanto no que se refere às relações em que ela apresentou dificuldades, quanto nas relações aprendidas posteriormente, uma vez que os ensinos seguintes também empregaram o procedimento de PO antes da exposição ao AMTS. Aparentemente, o PO aumentou a discriminabilidade dos estímulos modelo e comparação, facilitando o desempenho da idosa nas tarefas de emparelhamento ao modelo.

Os resultados de Fontanesi e Schmidt (2019) e os do presente estudo sugerem que, talvez, para idosos saudáveis em uma tarefa de aprendizagem de relações condicionais, tanto o PO quanto o AMTS são adequados como procedimentos de ensino. No entanto, efeitos diferentes podem ser observados quando se verifica uma dificuldade decorrente de algum transtorno, como ocorreu com a idosa que tinha afasia (Fontanesi \& Schmidt). Dificuldades na aprendizagem de relações condicionais via AMTS em idosos com algum tipo de transtorno neurocognitivo também foram relatadas em outros estudos (e.g., Ducatti \& Schmidt, 2016; Steingrimsdottir \& Arntzen, 2011; 2014), o que justifica a aplicação do PO associado ao AMTS em estudos futuros, conduzidos com indivíduos com algum TNC.

Ao longo do processo de ensino, observou-se que os blocos com maior número de repetições foram aqueles em que todas as quatro relações foram apresentadas juntas (bloco 5), e quando não foram fornecidas consequências diferenciais para os desempenhos (bloco 6). Nesses blocos, os participantes P8, P9, P10, P11 e P12 
necessitaram de, ao menos, uma repetição dos blocos, em pelo menos um dos procedimentos (e.g., P8 nos blocos 5 e 6, apenas em AMTS; P11, duas repetições nos blocos 5 e 6, nos dois procedimentos). Importante destacar que todos esses participantes, com exceção de P12, tinham a menor escolaridade da amostra.

Dificuldades em blocos de tentativas de AMTS que apresentam um conjunto de relações previamente ensinadas de forma separada já foram relatadas em outras pesquisas com idosos, com e sem transtornos neurocognitivos (e.g., Fontanesi \& Schmidt, 2019; Pérez-Gonzáles \& Moreno-Sierra, 1999; Sartori, 2008). Pérez-Gonzáles e Moreno-Sierra, por exemplo, compararam o desempenho de jovens e idosos na aprendizagem de relações condicionais visuais-visuais e em testes de equivalência. Os autores verificaram que os idosos repetiram mais os blocos de tentativas que apresentavam todas as relações ensinadas, assim como os blocos de tentativas em que a probabilidade de reforço de respostas corretas caiu para 50\%, em comparação com os indivíduos jovens.

Ainda não está claro o que pode ocasionar essa deterioração do desempenho dos idosos nesses dois tipos de blocos. No caso dos blocos em extinção, há vários registros na literatura que mostram esse mesmo efeito, sobretudo em crianças e em participantes com algum tipo de deficiência (e.g., Galvão, Calcagno, \& Sidman, 1992; Sidman, Wynne, Maguire \& Barnes, 1989). A falta de consequências diferenciais pode afetar desempenhos ainda não completamente estabelecidos, ou sinalizar, do ponto de vista do participante, erro (ainda que os participantes claramente sejam informados de que a ausência de consequências não sinaliza desempenhos incorretos), ou ainda desestabilizar algumas relações, que afetam as demais.

No caso dos blocos em que todas as relações são apresentadas em conjunto, talvez o treino de pares de relações não seja suficiente para que os participantes mais idosos consigam discriminar claramente entre os estímulos de comparação, ou seja, a 
discriminabilidade das fotos poderia ficar prejudicada em treinos separados (Fontanesi \&Schmidt, 2019). Essa dificuldade, então, seria explicitada na apresentação conjunta de todas as relações em um mesmo bloco. Essa hipótese, porém, precisa ser melhor investigada em estudos futuros.

Outro objetivo desse estudo foi verificar se os participantes, a partir da aprendizagem das relações condicionais, iriam apresentar desempenhos emergentes nos testes de equivalência e de nomeação. Os resultados mostraram que todos os participantes, em ambos os procedimentos de ensino, formaram classes de equivalência entre os estímulos. Um dado peculiar dessa pesquisa diz respeito à alta porcentagem de acertos dos idosos nos testes de equivalência, em ambos os procedimentos: tanto nos testes realizados logo após o ensino das relações, quanto nos testes de manutenção, a porcentagem média de acertos ficou acima de $98 \%$.

$\mathrm{Na}$ literatura específica sobre formação de classes de equivalência por idosos saudáveis, o desempenho dos participantes apresenta maior variabilidade em comparação aos resultados do presente estudo. O estudo de Haydu e Morais (2009), por exemplo, cujo objetivo era investigar o efeito do tamanho das classes de estímulos na formação e manutenção das classes de equivalência, demonstrou que dentre as 18 participantes idosas sem comprometimento cognitivo, cinco não formaram relações de equivalência logo após a fase de ensino: três delas não apresentaram essa formação quando a tarefa envolvia seis classes de estímulos, e duas quando forma testadas quatro classes de estímulos. As pesquisadoras observaram um maior índice médio de repetição dos blocos necessários para a aprendizagem das relações condicionais e a emergência das classes de equivalência quando as classes envolviam seis estímulos do que quando envolviam quatro. Nos testes de manutenção, 10 das 15 participantes continuaram a apresentar relações de equivalência para o conjunto com seis classes, e 11 das 16 para o conjunto com quatro classes de 
estímulos. De acordo com as autoras, o tamanho das classes teve influência apenas na manutenção das relações de equivalência para as classes com seis estímulos.

Aggio e Domeniconi (2012) também concluíram em seu estudo que classes equivalentes com maior número de estímulos emergem mais facilmente a partir do ensino, em comparação com classes formadas a partir de um número menor de estímulos. Todos os oito participantes da pesquisa apresentaram emergência de relações de equivalência entre os estímulos, porém, diferentemente do presente estudo, a emergência dessas relações foi imediata para quatro participantes apenas. Dois participantes apresentaram equivalência após uma repetição de bloco, um participante após cinco repetições, e outro participante após oito repetições de bloco.

Essas duas pesquisas não apresentam informações acerca da escolaridade nem sobre o desempenho dos participantes no MEEM, por isso não é possível traçar uma relação clara entre os resultados apresentados e o nível de escolaridade dos participantes nessas diferentes pesquisas (incluindo a aqui discutida). No entanto, várias pesquisas têm indicado que, especialmente a escolaridade, parece ser uma variável decisiva no desempenho de idosos saudáveis em diferentes tarefas que demandam habilidades ditas “cognitivas".

Autores ligados às neurociências têm descrito extensivamente os efeitos do envelhecimento sobre a integridade do cérebro (e.g., Rabitt \& Lowe, 2006; Stern, 2006; Valenzuela, 2008). Segundo esses autores, o processo de envelhecimento normal compreende gradientes de perda neuronal diferenciados para cada região neuroanatômica, com redução da atividade metabólica em circuitos específicos. Consequentemente, certas funções cognitivas sofrem mais impacto que outras, como por exemplo habilidades requeridas em tarefas que envolvem a manipulação rápida de conteúdos e materiais usando novas estratégias, ou que requeiram manipulação abstrata da informação recebida 
(Caixeta \& Pinto, 2014). Essas estratégias, porém, parecem ser muito relacionadas à escolaridade, que não é homogênea entre os idosos.

A escolaridade e as experiências intelectuais (como o tipo de ocupação do indivíduo ao longo da vida) têm sido fortemente relacionadas a um construto conhecido como reserva cognitiva (Cabral et al., 2016), que se refere a diferenças individuais na capacidade dos indivíduos em lidar com danos ao sistema nervoso (Stern, 2009). Notadamente a escolaridade tem sido estudada como um fator protetor importante para eventuais dificuldades cognitivas associadas ao envelhecimento.

Ostrosky-Solis et al. (1998), analisaram o efeito da variável escolaridade em desempenhos de indivíduos de diferentes faixas etárias em testes neuropsicológicos. No primeiro estudo, os pesquisadores compararam três amostras de diferentes faixas etárias e níveis de escolaridade (analfabetos, 1 a 2 anos e 3 a 4 anos de escolaridade). O instrumento utilizado foi o Neuropsi - Neuropsychological Test Battery, que avalia nove habilidades cognitivas em 26 testes. Em geral, os resultados mostraram que a escolaridade exerceu maior influência no desempenho dos participantes do que a faixa etária, sendo que quanto maior o nível educacional, melhor o desempenho. Os autores afirmaram que, em pelo menos três testes (compreensão da linguagem, fluência verbal e similaridades), apenas um ou dois anos de escolaridade aumentavam significativamente a performance dos participantes em relação aos demais que nunca haviam frequentado a escola. No segundo estudo os pesquisadores aumentaram as faixas de escolaridade: 0 anos, 1 a 4 anos, 5 a 9, e 10 a 19 anos de escolaridade. Em todos os testes, exceto o de orientação espacial, os escores dos participantes testados aumentaram com o aumento das faixas de escolaridade.

Outro estudo que comparou o declínio cognitivo ao longo do processo de envelhecimento normal com a variável educação foi o de Ardilla et al. (2000). Os 883 
participantes foram divididos em quatro grupos de idade (16 a 30 anos; 31 a 50; 51 a 65; 66 a 85 anos de idade), e quatro níveis de escolaridade ( 0 anos ou analfabetos; 1 a 4 anos; 5 a 9 anos; mais de 10 anos de escolaridade). Esses pesquisadores utilizaram os mesmos testes neuropsicológicos (Neuropsi) para a avaliação cognitiva, e apresentaram resultados semelhantes: a variável escolaridade teve maior influência no desempenho dos participantes do que a faixa etária. A conclusão do estudo foi que tanto o declínio, quanto o desenvolvimento cognitivo, estavam associados ao nível educacional, uma vez que as habilidades cognitivas avaliadas na maioria dos testes neuropsicológicos (por exemplo, nomear objetos, desenhar/copiar uma figura, tarefas de adição e subtração) são parcialmente aprendidas e muito treinadas nas atividades escolares.

Os resultados apresentados por Ardilla et al. (2000) e por Ostrosky-Solis et al. (1998) sugerem fortemente que a escolarização formal (assim como o tipo de ocupação desempenhada pelo indivíduo ao longo da vida e sua atividade intelectual) podem exercer grande influência em determinados tipos de tarefa, e talvez a formação de classes de equivalência exija algum tipo de desempenho fortemente influenciado por essas variáveis. Os resultados do presente estudo corroboram os dados apresentados na literatura, entretanto, recomenda-se que outras pesquisas com participantes idosos, envolvendo o paradigma da equivalência de estímulos, analisem eventuais relações entre o nível de escolaridade e o desempenho dos participantes.

Outro resultado importante que os resultados desse estudo mostraram foi o bom desempenho dos participantes nos testes de nomeação realizados logo após os blocos de ensino e teste (N1 e N2). As médias de acertos em N1 e N2, para todos os participantes, ficaram acima de $91 \%$ após o ensino por AMTS, e acima de 99\% após o ensino por PO. No entanto, houve uma queda nos desempenhos nos testes de manutenção, com uma diferença entre os participantes com nível de escolaridade até o ensino fundamental e os 
participantes que completaram o ensino médio: no procedimento de AMTS, as médias de acerto foram, respectivamente, $38 \%$ e $76 \%$; no PO as médias foram, respectivamente, $66 \%$ e $80 \%$.

A nomeação como um repertório emergente, após o ensino com matching-tosample, foi verificada em várias pesquisas com diferentes participantes, como pesquisas sobre leitura com crianças (Costa, Grisante, Domeniconi, de Rose, \& de Souza, 2013; de Rose, de Souza, \& Hanna, 1996; Gomes, Benitez, Domeniconi, \& Almeida-Verdu, 2017;), ou com crianças com implante coclear (Almeida-Verdu \& Gomes, 2016; Pereira, Assis, Palheta Neto, \& Almeida-Verdu, 2018). O mesmo não ocorre em pesquisas que avaliam o desempenho de nomeação em idosos, com ou sem comprometimento cognitivo, pois os poucos dados encontrados na literatura são variáveis.

Ducatti e Schmidt (2016 - Estudo 1) realizaram estudos com cinco participantes idosos saudáveis, e verificaram a ocorrência de nomeação emergente logo após o ensino por AMTS (porcentagem de acertos acima de 85\%). Esse é o único registro de testes de desempenhos emergentes de nomeação, com idosos saudáveis, após o ensino de relações arbitrárias via matching-to-sample. No entanto, outros estudos que têm testado nomeação em indivíduos idosos com comprometimento cognitivo, constataram desempenhos muito pobres em nomeação, mesmo logo após o ensino, e após a emergência de equivalência (Ducatti \& Schmidt, 2016 - Estudo 2; Fontanesi \& Schmidt, 2019).

Dessa forma, os resultados do presente estudo que mostram a emergência do desempenho de nomeação em idosos saudáveis, logo após o ensino, estão em conformidade com os resultados de Ducatti e Schmidt (2016 - Estudo 1). Porém, nenhum desses estudos testou o desempenho de nomeação na fase de manutenção. O presente estudo mostrou que, em geral, na fase de manutenção ocorre uma queda no desempenho de todos os participantes. Mas, essa queda foi mais acentuada nos participantes com 
menor escolaridade, sugerindo que, possivelmente, a escolarização tenha relação com a manutenção desse desempenho: é possível que a escolarização confira aos idosos a possibilidade de empregar estratégias que aumentem a discriminabilidade dos estímulos visuais (como, por exemplo, utilizar uma fala encoberta que destaque certa característica física da pessoa fotografada), facilitando a memorização de determinadas características de cada estímulo e sua nomeação. Indivíduos com menor escolarização provavelmente tiveram menos oportunidades de treino para o desenvolvimento desse tipo de estratégia; portanto, na idade mais avançada, apresentam mais dificuldade nesse tipo de tarefa.

Uma ponderação deve ser feita com relação ao presente estudo, pois a amostra de idosos com baixa escolaridade é menor (quatro participantes) em comparação à amostra de participantes mais escolarizados. Para testar essa hipótese da influência da escolarização no desempenho de nomeação, na fase de manutenção, seria necessária uma amostra de idosos maior e mais equilibradas em termos de escolarização.

Apesar de não terem sido verificadas diferenças nos desempenhos gerais dos idosos nos dois procedimentos, os resultados dos testes de nomeação evidenciam desempenhos melhores após o procedimento de ensino por PO. No caso dos participantes com menor nível de escolaridade, esse procedimento parece ter favorecido a manutenção do desempenho de nomeação em comparação ao procedimento de AMTS.

Em sua teoria, Stemmer (1992) afirma que uma extensão genérica da exposição ao evento ostensivo é a generalização de classes, pois o comportamento de emitir a palavra correta diante de um estímulo é evocado não apenas diante de estímulos idênticos, mas também com estímulos similares. Uma vez que sua teoria foi desenvolvida especificamente como um modelo explicativo da aquisição do comportamento verbal em crianças, talvez o PO possa facilitar a emissão de desempenhos emergentes na formação de classes de equivalência em populações com dificuldade de aprendizagem, inclusive 
idosos com algum tipo de comprometimento cognitivo. Algo semelhante pode ocorrer com o desempenho emergente de nomeação (apesar de o autor não ter explorado essa habilidade): repetidas exposições ao pareamento do estímulo verbal com o estímulo nãoverbal podem fazer com que a presença do estímulo visual evoque o desempenho de nomear em indivíduos com dificuldade de aprendizagem. Essas hipóteses são bastante genéricas e devem ser testadas em outras pesquisas que investiguem o PO como procedimento de ensino para indivíduos que apresentem algum tipo de dificuldade de aprendizagem (como os idosos em estágios iniciais do declínio cognitivo).

Entre as limitações desse estudo, pode-se citar a maior representação de mulheres: entre os 12 participantes, havia apenas um homem. Entretanto, é preciso considerar que população idosa é composta por mais mulheres (56\%) do que homens (44\%) (IBGE, 2018). Além de haver mais mulheres acima de 55 anos de idade do que homens (de acordo com o censo do IBGE de 2010, a razão é de 82,6 homens para cada 100 mulheres, a pesquisadora teve maior facilidade em encontrar participantes do sexo feminino. Por outro lado, há indicativos na literatura de que mulheres são mais resilientes aos efeitos do declínio cognitivo em comparação aos homens ao longo do envelhecimento (McCarrey, An, Kitner-Triolo, Ferrucci, \& Resnick, 2016), o que pode ser visto como um eventual viés desta pesquisa. Visto que outras pesquisas envolvendo idosos e com procedimentos semelhantes foram realizadas apenas com participantes do sexo feminino (e.g., Haydu \& Morais, 2009; Steingrimsdottir \& Arntzen, 2014), recomenda-se que estudos futuros sejam realizados com a mesma quantidade de participantes de ambos os sexos para que esta variável também seja investigada.

O presente estudo sugere uma série hipóteses sobre a influência do nível de escolaridade no desempenho de idosos, tanto em tarefas de aprendizagem de relações condicionais, quanto na manutenção de desempenhos emergentes. Considerando que o 
número de idosos nesse trabalho é pequeno, impedindo que conclusões mais robustas sejam feitas, é recomendável a ampliação desse estudo para amostras maiores, envolvendo grupos mais homogêneos com relação à diferença na escolarização dos participantes. Estudos comparativos desse gênero podem ajudar a elucidar o papel da escolaridade nas tarefas aqui estudadas.

Além disso, considerando que todos os idosos conseguiram aprender as relações ensinadas, tanto por AMTS, quanto por AMTS após a exposição ao PO, sugere-se que a continuidade desse estudo seja realizada em pesquisas com idosos que apresentem comprometimento cognitivo, para verificar se haverá a mesma eficácia desses dois procedimentos de ensino na aprendizagem e manutenção de relações arbitrárias, e se o PO terá um efeito facilitador para essa população. 


\section{Referências}

Agência de Notícias IBGE. (2018). Número de idosos cresce $18 \%$ em cinco anos e ultrapassa 30 milhões em 2017. Recuperado em 6 março, 2019, de https://agenciadenoticias.ibge.gov.br/agencia-noticias/2012-agencia-de noticias/ noticias/20980-numero-de-idosos-cresce-18-em-5-anos-e-ultrapassa-30-milhoes-em $-2017$

Aggio, N. M., \& Domeniconi, C. (2012). Formação e manutenção de classes de estímulos equivalentes: Um estudo com participantes da terceira idade. Acta Comportamentalia, 20, 29-43.

Almeida-Verdu, A. C. M.., \& Gomes, F. P. (2016). Precisão da fala em nomeação de figuras após formação de classes de equivalência em crianças com implante coclear. Perspectivas em Análise do Comportamento, 7(2), 274-287.

Ardilla, A., Ostrosky-Solis, F., Rosselli M., \& Gómez, C. (2000). Age-related cognitive decline during normal aging: The complex effect of education. Archives of Clinical Neuropsychology, 17(3), 205-210.

Brandão, L., Lima, T. M., Pereira, N., Pagliarin, K. C., \& Fonseca, R. P. (2014). Reabilitação da linguagem no idoso. In L. Caixeta \& A. L. Teixeira (Orgs.), Neuropsicologia geriátrica: Neuropsiquiatria cognitiva em idosos. (pp. 311-323). Porto Alegre, RS: Artmed.

Cabral, J. C. C., Veleda, G. W., Mazzoleni, M., Colares, E. P., Neiva-Silva, L., \& Neves, V. T. D. (2016). Stress and cognitive reserve as independent factors of neuropsychological performance in healthy elderly. Ciência \& Saúde Coletiva, 21, 3499-3508.

Caixeta, L. \& Pinto, P. H. (2014). Reserva cerebral, plasticidade e o cérebro do idoso. In L. Caixeta, \& A. L. Teixeira (Orgs.). Neuropsicologia geriátrica: Neuropsiquiatria cognitiva em idosos (pp. 45-55). Porto Alegre, RS: Artmed.

Costa, A. R. A., Grisante, P. C., Domeniconi, C., de Rose, J. C., \& de Souza, D. G. (2013). Naming new stimuli after selection by exclusion. Paidéia, 23(55), 217-224.

Dahás, L. J. S., Goulart, P. R. K., \& Souza, C. B. A. (2008). Pode o comportamento do ouvinte ser considerado verbal? Revista Brasileira de Terapia Comportamental e Cognitiva, 10(2), 281-291.

de Rose, J. C. (1993). Classes de estímulos: Implicações para uma análise comportamental da cognição. Psicologia: Teoria e Pesquisa, 9(2), 283-303.

de Rose, J. C., \& Bortoloti, R. (2007). A Equivalência de estímulos como modelo de significado. Acta Comportamentalia, 15, 83-102.

de Rose, J. C., de Souza, D. G. \& Hanna, E. S. (1996). Teaching reading and spelling: Exclusion and stimulus equivalence. Journal of Applied Behavior Analysis, 29(4), 451-469. 
Dixon, L. S. (1977). The nature of control by spoken words over visual stimulus selection. Journal of the Experimental Analysis of Behavior, 27, 433-442.

Ducatti, M., \& Schmidt, A. (2016). Learning conditional relations in elderly people with and without neurocognitive disorders. Psychology \& Neuroscience, 9(2), 240-254.

Folstein, M. F., Folstein, S. E., \& McHugh. (1975). Mini-Mental State: A practical method for grading the cognitive state of patients for the clinician. Journal Psychiatric, 12, 189-198.

Fontanesi, S. R. O., \& Schmidt, A. (2019). Ensino de relações condicionais por pareamento auditivo-visual e exclusão para uma idosa com afasia fluente. Acta Comportamentalia, 27(1), 73-89.

Galvão, O.F., Calcagno, S., \& Sidman, M. (1992). Testing for emergent performance in extinction. Experimental Analysis of Human Behavior Bulletin, 10 (2), 18-20.

Gomes, M. L. C., Benitez, P., Domeniconi, C., \& Verdu, A. C. M. A. (2017). Efeitos do ensino do ecoico aliado a repertórios básicos de leitura sobre a nomeação de palavras em crianças com deficiência intelectual. Temas em Psicologia, 25(1), 319-334.

Haydu, V. B., \& Morais, L. P. (2009). Formação, manutenção e recuperação de relações equivalentes em adultos da terceira idade. Psicologia Argumento, 27 (59), 323-336.

Instituto Brasileiro de Geografia e Estatística. (2010). Estatísticas de gênero. Recuperado em 6 março, 2019, de https://www.ibge.gov.br/apps/snig/v1/?loc=0\&cat=$2,60,128 \&$ ind $=4708$

Instituto Brasileiro de Geografia e Estatística (2015). Mudança demográfica no Brasil no início do século XXI. Recuperado em 6 julho, 2016, de http://biblioteca.ibge.gov.br/visualizacao/livros/liv93322.pdf

McCarrey, A. C., An, Y., Kitner-Triolo, M. H., Ferrucci, L., \& Resnick, S. M. (2016). Sex differences in cognitive trajectories in clinically normal older adults. Psychology and Aging, 31(2), 166.

Ostrosky-Solis, F., Ardila, A., Rosselli, M., Lopez-Arango, G., \& Uriel-Mendonza, V. (1998). Neuropsychological test performance in illiterate subjects. Archives of Clinical Neuropsychology, 13(7), 645-660.

Pereira, F., Assis, G. J., Palheta Neto, F., \& Almeida-Verdu, A. C. M. (2018). Emergência de nomeação bidirecional em criança com implante coclear via Instrução com Múltiplos Exemplares (MEI). Revista Brasileira de Terapia Comportamental $e$ Cognitiva, 20(2), 26-39.

Pérez-González, L. A., \& Moreno-Sierra, V. (1999). Equivalence class formation in elderly persons. Psicothema, 11(2), 325-336.

Porto, F. H. G., \& Nitrini, R. (2014). Neuropsicologia do envelhecimento normal e do comprometimento cognitivo leve. In L. Caixeta, \& A. L. Teixeira (Orgs.), Neuropsicologia geriátrica: Neuropsiquiatria cognitiva em idosos (pp. 141-152). Porto Alegre, RS: Artmed. 
Rabbit, P., \& Lowe, C. (2006). Patterns of cognitive ageing. Psychological Research, 63(3-4), 308-316.

Sartori, R. M. (2008). Aprendizagem discriminativa e comportamento simbólico de jovens, idosos com desenvolvimento típico e idosos com Alzheimer. Dissertação de Mestrado, Universidade Federal de São Carlos, São Carlos, SP, Brasil.

Sidman, M. (1994). Equivalence relations and behavior: A research story. Boston: Authors Cooperative.

Sidman, M., \& Tailby, W. (1982) Conditional discrimination vs. matching-to-sample: an expansion of the testing paradigm. Journal of the Experimental Analysis of Behavior, $37(1), 5-22$.

Sidman, M., Wynne, C.K., Maguire, R.W., \& Barnes, T. (1989). Functional classes and equivalence relations. Journal of the Experimental Analysis of Behavior, 52, 261274.

Simon, S. S., \& Ribeiro, M. P. O. (2011). Comprometimento cognitivo leve e reabilitação neuropsicológica: uma revisão bibliográfica. Psicologia Revista, 20(1), 93-122.

Sousa, N. M., Souza, C. B. A., \& Gil, M. S. C. A. (2013). Aprendizagem rápida de comportamento de ouvinte por um bebê. Interação em Psicologia, 17(1), 67-78.

Souza, C. B. A., Miccione, M. M., \& Assis, G. J. A. (2009). Relações autoclíticas, gramática e sintaxe: O tratamento skinneriano e as propostas de Place e Stemmer. Arquivos Brasileiros de Psicologia, 61(1), 121-131.

Steingrimsdottir, H. S., \& Arntzen, E. (2011). Using conditional discrimination procedures to study remembering in a Alzheimer's patient. Behavioral Interventions, 26, 179-192.

Steingrimsdottir, H. S., \& Arntzen, E. (2014). Discrimination learning in adults with neurocognitive disorders. Behavioral Interventions, 29, 241-252.

Stemmer, N. (1992). The behavior of the listener, generic extensions, and the communicative adequacy of verbal behavior. The Analysis of Verbal Behavior, 10, 69-80.

Stern, Y. (2006). Cognitive reserve and Alzheimer disease. Alzheimer Disease and Associated Disorders, 20(2), 112-117.

Stern, Y. (2009). Cognitive reserve. Neuropsychology, 47(10), 2015-2028.

Valenzuela, M. J. (2008). Brain reserve and the prevention of dementia. Current Opinion in Psychiatry, 21(3), 296-302.

Vichi, C., Nascimento, G. S., \& Souza, C. B. A. (2012). Aprendizagem ostensiva, comportamento de ouvinte e transferência de função por pareamento de estímulos. Revista Brasileira de Terapia Comportamental e Cognitiva, 14(1), 16-30.

World Health Organization. (2016). Mental health and older adults. Recuperado em 9 julho, 2016, de http://www.who.int/mediacentre/factsheets/fs381/en/ 
World Health Organization. (2017). Dementia. Recuperado em 17 fevereiro, 2018, de https://www.who.int/news-room/fact-sheets/detail/dementia

Yeoman, M., Scutt, G., \& Faragher, R. (2012). Insights into CNS ageing from animal models of senescence. Nature Reviews Neuroscience, 13(6), 435-445.

Yesavage, J.A., Brink, T.L., Rose, T.L., Lum, O., Huang, V., Adey, M., \& Leirer, V. O. (1983). Development and validation of a geriatric depression screening scale: A preliminary report. Journal of Psychiatric Research, 17, p. 37-49. 


\begin{abstract}
ANEXO 1
Entrevista Semi-Estruturada - Participante de Pesquisa
\end{abstract}

1. Dados Pessoais

Nome:

Data de nascimento:

Idade:

Endereço:

Telefone:

Escolaridade:

Profissão:

Estado Civil:

2. Reside com:

Nome/ Parentesco/ Profissão/ Idade

3. Informações sobre a rotina (atividades, funções na casa, etc...).

4. Realiza algum tratamento? Se sim, qual? Qual a medicação utilizada?

5. Observações: 
ANEXO 2 - TCLE

\section{TERMO DE CONSENTIMENTO LIVRE E ESCLARECIDO}

Meu nome é Maria Cláudia Ristum e estou realizando uma pesquisa de mestrado que tem como título "Comparação de procedimentos de ensino de relações nome-face para idosos saudáveis", sob a orientação da profa. Dra. Andréia Schmidt, professora da Pós-Graduação em Psicobiologia da Universidade de São Paulo.

Nessa pesquisa estamos estudando maneiras de ajudar pessoas com mais de 60 anos de idade, que tenham problemas de memória ou dificuldades para dizer o nome de pessoas ou de objetos conhecidos. Para isso, testaremos dois métodos para ensinar relações entre fotos de pessoas desconhecidas e seus nomes, com a ajuda de um computador. Esse ensino será feito em etapas, ao longo de alguns dias. A duração total desse procedimento será de aproximadamente um mês, por aproximadamente 30 minutos com cada participante, sendo que as sessões de ensino ocorrerão nos dias da semana em que este tiver maior disponibilidade.

Se você aceitar participar dessa pesquisa, primeiramente faremos uma avaliação da sua memória e cognição (avaliando a capacidade de se localizar no tempo e no espaço, e de responder algumas questões de raciocínio lógico), por meio de dois testes. Também precisaremos avaliar se você apresenta sinais de depressão. Você terá acesso a todos os resultados desses testes através de uma conversa comigo, na qual poderá tirar suas dúvidas. Se você autorizar, os resultados destes testes poderão ser anexados à sua ficha na instituição onde reside.

A pesquisa não envolverá nenhum custo, assim como não haverá nenhum pagamento, nem para o participante e nem para a instituição. Da mesma forma não há riscos previstos à saúde e ao bem-estar dos participantes que concordarem em participar. Talvez você possa se sentir um pouco cansado durante as sessões de ensino, mas, se isso acontecer, basta que você me avise e interromperemos a atividade sem que isso traga qualquer prejuízo para você ou para a pesquisa.

A identidade dos participantes e da instituição não será divulgada e os resultados da pesquisa serão usados exclusivamente para fins científicos, ou seja, para o desenvolvimento de estratégias de ensino que possam ajudar pessoas idosas que apresentem problemas de memória e linguagem. Esses resultados serão apresentados em congressos científicos sem, contudo, identificar os participantes. Você pode desistir de 
participar do estudo a qualquer momento, sem que isso cause qualquer problema ou dificuldade na sua relação com a pesquisadora ou com a instituição onde reside.

O benefício esperado com a pesquisa é o desenvolvimento de novas formas de ajudar idosos com perda de memória a recuperar a capacidade de nomear objetos e pessoas.

Garantimos que você poderá ter acesso aos dados da pesquisa ou esclarecer possíveis dúvidas em qualquer momento que desejar, bastando, para isso, entrar em contato com as pesquisadoras por meio dos telefones abaixo descritos, ou pessoalmente, uma vez que a coleta de dados ocorrerá nas dependências da própria instituição. Você ficará com uma via desse Termo de Consentimento, e a outra via será arquivada pelo pesquisador. Para qualquer dúvida ou denúncia em relação aos aspectos éticos da pesquisa, o Comitê de Ética em Pesquisa pode ser contatado no seguinte endereço: CEP - Comitê de Ética em Pesquisa da FFCLRP USP - Avenida Bandeirantes, 3900 - Bloco 23 - Casa 37 - 14040-901 - Ribeirão Preto - SP . Fone: (16) 3315-4811 / Fax: (16) 36332660. E-mail: coetp@ffclrp.usp.br / homepage: http://www.ffclrp.usp.br

Se você concordar em participar dessa pesquisa, por gentileza assine esse termo de consentimento. Desde já, agradecemos a sua atenção e disponibilidade.

$\mathrm{Eu}$,

portador do $\mathrm{RG} \mathrm{n}^{\circ}$ , aceito participar da pesquisa acima descrita. Declaro que fui esclarecido(a) sobre os procedimentos envolvidos e que tenho sob minha guarda uma via desse termo de consentimento.

Ribeirão Preto, de de 201_.

Assinatura do Participante

Pesquisadoras:

Maria Cláudia M. Ristum RG: 43.459.775-2

End.: Rua Arnaldo Victaliano, 881 Telefone: (16) 98159-8155
Andréia Schmidt

RG: 2243897

Endereço: Av. Bandeirantes, 3900

Tel: (16) 3315-3742 